\section{SPRU}

Science and Technology

Policy Research
Working Paper Series SWPS 2013-04

September, 2013

\title{
The multi-dimensional additionality of
}

innovation policies. A multi-level application to Italy and Spain

Alberto Marzucchi

Sandro Montresor 


\title{
SPRU Working Paper Series
}

The SPRU Electronic Working Paper Series aims to accelerate the public availability of the research undertaken by SPRU-associated people of all categories, and exceptionally, other research that is of considerable interest within SPRU. It presents research results that in whole or part are suitable for submission to a refereed journal, to a sponsor, to a major conference or to the editor of a book. Our intention is to provide access to early copies of SPRU research.

\section{Editors}

Tommaso Ciarli

Daniele Rotolo

Associate Editors
Florian Kern
Paul Nightingale
Matias Ramirez
Joe Tidd \&
Carlos Sato
Maria Savona \&
Mariana Mazzucato

Andrew Stirling

Area

Energy
Transitions

Science, \& Technology Policy

Development

Technology Innovation Management

Economics of Technological Change

\section{Administrator}

Jenny Lieu

\author{
J.Lieu@sussex.ac.uk
}

M.Savona@sussex.ac.uk

M.Mazzucato@sussex.ac.uk

A.C.Stirling@sussex.ac.uk

\section{Contact \\ T.Ciarli@sussex.ac.uk \\ D.Rotolo@sussex.ac.uk}

F.Kern@sussex.ac.uk

P.Nightingale@sussex.ac.uk

Matias.Ramirez@sussex.ac.uk

J.Tidd@sussex.ac.uk

C.E.Y.Sato@sussex.ac.uk

uk

(1)

(1)

(1)

\section{Disclaimer}

The works available here are the responsibility of the individual author(s) and do not necessarily represent the views of other SPRU researchers. As matters of policy and practice, SPRU does not endorse individual research contributions.

\section{Guidelines for authors}

Papers shall be submitted in pdf or Word format. They should contain a title, an abstract, and keywords. Papers should be submitted to one of the Editors, who will process them and send them to the appropriate Associate Editor. Two members of SPRU will be asked to provide a short written review within three weeks. The revised versions of the paper, together with a reply to the reviewers, should be sent to the Associate Editor, who will propose to the Editors its publication on the series. When submitting the authors should indicate if the paper has already undergone peerreviewing, in which case the Associate Editors may decide to skip internal review process.

\section{Website}

SWPS: www.sussex.ac.uk/spru/research/sewps

IDEAS: ideas.repec.org/s/sru/ssewps.html 


\title{
The multi-dimensional additionality of innovation policies. A multi-level application to Italy and Spain.
}

\author{
Alberto Marzucchi ${ }^{1}$ and Sandro Montresor ${ }^{2}$ \\ October 2012 \\ Preliminary - Do not quote without prior permission \\ SPRU, Science and Technology Policy Research \\ Jubilee Building, University of Sussex, \\ Falmer, Brighton, BN1 9SL, UK
}

\begin{abstract}
The paper proposes and applies an original multi-dimensional evaluation of the additionality of innovation policy, which takes into account its multi-level nature. The input, output and behavioural additionality effects of innovation policies (multidimension) are jointly investigated, at the national and regional level (multi-level). An empirical application is carried out for Italy and Spain. A propensity score matching estimation of the average treatment effect on the treated (ATT) is carried out, by using the $4^{\text {th }}$ Community Innovation Survey (CIS). The two multi-level systems of policies appear quite different, both in the extent to which their additionality affects the different dimensions, and to which it does it at the two levels of government.

Regional policies miss input additionality in both countries, while they show output additionality in Spain only, where they are also able to spur innovative behaviours by the treated firms. National policies show output additionality in both countries, but in terms of different variables in Spain (product innovations) and in Italy (process innovations). Overall, only national policies show full multi-dimensionality in their additionality. Behavioural additionality has an opposite cross-level nature in the two countries: full additionality in Spain, but full crowding-out in Italy.
\end{abstract}

Key words: innovation policy, additionality, innovation system, multi-level policy JEL codes: 031, 038, R58, 025, 057

\footnotetext{
1 Faculty of Political Sciences, Catholic University of Milan (Italy) \& INGENIO (CSIC-UPV), Universitat Politècnica de València (Spain).

${ }^{2}$ JRC-IPTS, European Commission, Seville (Spain) \& Department of Economics, University of Bologna (Italy).

Correspondence address: Sandro Montresor, Department of Economics, University of Bologna (Italy), Strada Maggiore 45, 40125 Bologna. Email: sandro.montresor@unibo.it
} 


\section{Introduction}

Two contrasting forces currently characterise innovation policy in EU countries. On the one hand, the public support to innovation is necessary to reach the targets of the Europe 2020 strategy (European Commission, 2010). On the other hand, the recent economic crisis spurs governments to control their public debts and to increase the effectiveness and the efficiency of their interventions in innovation. In this scenario, the evaluation of innovation policies is of great importance to take stock of the outcome of previous initiatives, and use them to calibrate current actions and plan future ones.

The present paper contributes to the empirical analysis of the impact of innovation policy. Its main aim is to investigate the so-called "additionality" of the public support to firms' innovation with three elements of originality. Firstly, we adopt a multidimensional approach to additionality and address the effects that the policy can have with respect to three dimensions of the innovative process: that is, innovative efforts (input), results (output), and behaviours. Secondly, we follow a multi-level perspective and consider the interplay between the effects of innovation policies devised at two levels: that is, national and regional. Thirdly, we use a comparative methodology and provide more systematic evidence than the one emerging from individual case-studies.

The empirical application of the paper refers to two European countries, Italy and Spain, which are increasingly often compared in terms of economic-innovation performance and of policy-governance (mainly, the interplay between national and regional level). Their choice is motivated, among the others, by the intention of providing results which could be useful to the policy-learning process that occurs though the interaction of two neighbouring countries.

A set of Propensity Score Matching (PSM) techniques is applied to microdata on manufacturing firms coming from the fourth wave (2002-2004) of the Community Innovation Survey. Although the cross-sectional nature of these data limits the possibility to overcome (completely) the potential endogeneity of the policy, the PSM allows us to control for presence of a selection bias on the observables.

The reminder of the paper is organised as follows. Section 2 reviews the additionality concept and illustrates the three dimensions along which innovation policy will be evaluated. Section 3 discusses the multi-level features of innovation policies, and the implications that the existence of a national and regional level of policy has for its additionality evaluation. Section 4 illustrates the empirical application and Section 5 discusses its results. Section 6 concludes. 


\section{The multi-dimensional additionality of innovation policy}

In the standard neoclassical approach, public policy is called to remedy the firms' underinvestment in innovation, namely in $\mathrm{R} \& \mathrm{D}$, generated by market failures. ${ }^{3}$ According to the linear model of innovation, which also characterizes the neoclassical approach (Edquist, 1999), the underinvestment in $R \& D$ would result in an underproduction of innovation. Hence, public interventions should be eventually directed also to increasing the firms' innovation outputs.

Following this perspective, innovation policy can be evaluated by simply assessing its "additionality" in terms of innovative inputs and outputs. Input additionality concerns the amount of resources (for example, R\&D investments) that firms would not have allocated to the innovation process in the absence of policy (Georghiou, 2004; Clarysse et al. 2004; Cerulli, 2010). In brief, this is the additional amount of private, innovative inputs brought about by the policy: in the case of $R \& D$, for example, this is an additional monetary amount. Output additionality instead concerns the innovative outcomes that firms would not have achieved without the public support (Georghiou and Clarysse, 2006). This is the additional amount of private, innovative outputs brought about by the policy. These outputs can be both the direct result of the innovative projects supported by the public intervention (for example, new products, processes and patents) and their "indirect" economic outcomes (that is, improved business performances, resulting from the introduction of new products or processes) (Georghiou, 2002).

Although quite straightforward, the sole evaluation of the input and output additionality of the policy is affected by an important conceptual limitation. Those firms which benefit from the policy are treated as "black-boxes". The process through which they transform innovative inputs into outputs is treated as automatic and not explored. However, as the evolutionary theory (Nelson and Winter, 1982) and the related innovation system perspective (Edquist, 1999) have shown since long, this is not the case. On the contrary, firms innovate by adopting a set of learning behaviours which affect, first of all, their internal organization. For example, they invest in human capital and in other intangibles innovative drivers, such as design, brand and reputation, and organizational capital. Furthermore, they learn by interacting with the relevant institutional environment: for example, through technology transfer and innovation cooperation .

All these behaviours can be exposed to additional failures, which have been called system failures (Metcalfe, 1995; Smith, 2000). For example, firms might be unable to develop the internal competencies to adapt to new technological developments. They could lack proper hard (e.g. regulations and legal systems) and soft (e.g. social values

\footnotetext{
${ }^{3}$ The semi-public good nature of technological knowledge and the information asymmetries which emerge in the relative transactions are the most relevant of these failures (Arrow, 1962).
} 
and culture) institutions for effective innovation cooperation (for a review of these failures, see Woolthuis et al., 2005).

System failures are also in need of policy intervention, although of a possibly different kind (on that, see Edquist, 2011). Accordingly, the evaluation of innovation policies should be integrated with the assessment of its additionality in terms of innovative behaviours. Behavioural additionality is defined by Buisseret et al. (1995) as "the change in a company's way of undertaking R\&D which can be attributed to policy actions" (p. 590). In other words, the evaluation of behavioural additionality considers whether the policy intervention induces relevant changes both in the internal organisation of the beneficiaries' innovation process and in their relationships with external sources of knowledge. More precisely, the focus can be on: the improvement of capabilities, the enhancement of beneficiaries' networking and interactions with other organisations; the acquisition of new and diverse knowledge that can mitigate lock-in positions into non-preferable technologies ${ }^{4}$ (e.g. Antonioli and Marzucchi, 2012; Georghiou and Clarysse, 2006; Hall and Maffioli, 2008; Breschi et al., 2009).

It should be stressed that, with respect to each of the three dimensions, the actual detection of the additionality of the policy is just a possible outcome of its search. As we will see, the nil hypothesis of the relative test is that the policy does not bring about any significant additional effect (with respect to similar, non treated firms). In brief, it could be ineffective. However, the additionality effect could even be significantly negative. The policy could reduce the amount of innovative inputs, outputs and behaviours that firms would have chosen in the absence of it. Also in the innovation realm, by remedying to private failures, policy makers could bring about public failures, which can crowd-out the firms' inputs, outputs and behaviours (Edquist et al., 2004: 430-431; Hommen and Equist, 2008; Tamm, 2010).

As we will see, when it is significant, the additionality of the policy can be quantified. Its measurement can be used to assess the depth of the policy impact, on each of the three considered dimensions. An additional evaluation can be made by looking at the width of the policy effects, with respect to the three dimensions. In other words, we can evaluate whether the policy has a widespread impact on the innovative process in which the supported firms are involved, or rather a focused one. ${ }^{5} \mathrm{~A}$ first explorative insight can be obtained, for example, by looking at the combination of outcomes that the three considered dimensions show in terms of additionality. In this last respect, the additionality of the policy can have different degrees of multi-dimensionality. In the

\footnotetext{
${ }^{4}$ Given the lack of proper data this third type of effect is not considered in the following analysis. For an investigation of the capacity of the policy to stimulate the acquisition of diverse competencies see Antonioli et al. (2012).

${ }^{5}$ This kind of analysis could be considered introductory to the search of specific kind of relationships (for example, of complementarity and substitutability) between the different dimensions. An issue on which recent research is concentrating, with different approaches and results (e.g. Czarnitzki and Licht, 2006; Autio et al., 2008; Clarysse et al., 2009; Antonioli and Marzucchi, 2012).
} 
case of three additionality dimensions that we are considering (input, output and behaviour), we could have one of the following five scenarios.

(1) (Full) multi-dimensionality. The policy is able to simultaneously add innovative inputs, outputs and behaviours to those of the supported firms. The action of the policy makers has widespread effects on the innovation process, and can be considered, expost, an actual "system" kind of policy.

(2) Bi-dimensionality. Some additionality is detected for only two out of the three dimensions, with no significant effect on the third one. The policy makers have a partial impact on the innovative process, while one dimension of it remains out of their control, ex-ante and/or ex-post. In the case of both input and output additionality, policy makers will appear willing and/or capable to fully address but only market kind of failures. In the case of behavioural and input or output additionality, the policy has the minimum capacity of addressing failures of different kinds.

(3) Mono-dimensionality. The additionality of the policy is limited to only one of the three dimensions, while the remaining two are unaffected. The policy impact is quite focused (ex-ante and/or ex-post), either on one of the two cases of market failures (input or output), or on the sole failures which hampers the firms' innovative behaviours.

(4) Partial cross-dimensional crowding-out. This is a qualification that the policy gets when a negative additionality outcome emerges along one or two dimensions. However, the policy is still able to show an actual (that is, positive) additionality with respect to two, or at least one of them. In this kind of scenario the policy turns out to suffer from some trade-offs among the dimensions of its effects. For example, while adding to the firms' innovative efforts, it could decrease their need/incentive to undertake innovative behaviours. Because of these trade-offs, although it could be effective to a certain extent, the policy will inevitably have only a second-best kind of outcome, in terms of width of its effects.

(5) Full cross-dimensional crowding-out. The policy does not have any significant impact but one or even more negative additionality effects. The case is one of public failure in innovation. Not only misses the public sector the capacity to solve the problems firms face in innovating. But it even exacerbates them, by making firms unable to stick to their pre-policy levels of innovative efforts, outcomes or behaviours.

\section{The multi-level system of policy}

Like in other fields, also in innovation, policy actions are undertaken at different levels of government: local, regional, national and super-national (for example, the EU level). Their coordination is thus of crucial importance to make the public support to innovation effective. Duplications of efforts need to be avoided, as well as action gaps in the search for the most appropriate level of interventions. 
At the EU level, policy-coordination is managed through the "subsidiarity principle". The Union intervenes only when a certain action cannot be achieved by the Member States either at the national, or at the regional and local level - and appears better achievable at the Union level. Economies of scale and externalities are the main elements which support this choice (European Commission, 2009).

Looking at innovation, further elements need to be considered, especially in the relationship between the national and the regional level. The question is not simply to determine which is the best level of government to support innovation, as it was in the early studies on regional innovation systems (RIS). The regional policy-maker was considered to be in a better position, with respect to the national one, to implement context-specific innovation strategies. In particular, the regional policy was recognised able to promote network-type of instruments to exploit those agglomeration advantages which are available in territorial clusters (Uyarra, 2010). An increasing attention to the regional level of policy has been justified by the idea that public intervention has to be "context-specific and sensitive to local path-dependency" (Amin, 1999, p. 368).

However, this viewpoint fails to take into account that, in innovation, the different levels of public support interact among them. As noted by Laranja et al. (2008), evolutionary processes of selection, generation of novelty and path-dependency occur at multiple geographical scales. Hence, there is not a unique optimal level in which innovation policy should be designed and delivered. Furthermore, innovation is a phenomenon that is shaped by institutional aspects pertaining to different scales too (Howells, 1999; Boschma, 2005b). In synthesis, public interventions should be seen as part of a multilevel system of policy or governance (Cooke, 2002; Kaiser, 2003), in which different support schemes are initiated at different levels.

This aspect of innovation policy is a crucial one, which must be considered also in evaluating its impact. This is particularly so if we follow a multi-dimensional perspective to additionality. It is important to determine whether regional and national interventions overlap in the effects they produce along the different additionality dimensions we have considered. In other words, the evaluation process should look at whether the two levels of policy are capable of inducing firms to "move towards the same direction", in terms of additionality effects.

In this respect, a simple exercise can be carried out. For each of the three dimensions input, output and behavioural - we can see whether, and eventually which kind of (positive or negative), additionality is brought about by regional and national schemes. The input, output and behavioural additionality of the policy could thus have one of the following four characterizations.

(1) Full cross-level additionality. The policy operates in an actual multi-level manner with respect to the relevant dimension. Both regional and national policy makers are able to affect it and thus operate complementarily on it. 
(2) Partial cross-level additionality. The relevant dimension shows additionality only at one of the two levels of government (national or regional), being the other level incapable of add something. This scenario would signal the existence of an "exclusive" policy-zone, which matches with the characteristics of the actions undertaken by only one kind (national or regional) of policy-makers.

(3) Partial cross-level crowding-out. Along a certain dimension, one policy level adds, while the other crowds it out. The dimension represents an even more exclusive policyzone, where the two levels appear misaligned and actually clash between them.

(4) Full cross-level crowding-out. Both levels of government make the firms' reduce their pre-policy involvement along the relevant dimension. The public failure appears general and possibly not due to the specificity of the policy level which has determined it.

By pooling together the evaluations obtained for each and every dimension, their average can give us a multi-level assessment at the country level. Its multi-level system of policy can thus also be characterised with respect to the above mentioned four specifications.

A third and final piece of analysis can be carried out by simultaneously considering the multi-level and the multi-dimensional specification of the policy additionality. This can be done by retaining the whole set of effects that regional and national policies have along the three dimensions, irrespectively from their matching. This can give us an insight of what can be considered the total cross-level additionality of innovation policy in a certain country. By adding a total cross-level specification, the five crossdimensional configurations illustrated in Section 2 returns to be a reference point for this evaluation.

\section{Empirical application}

The empirical application of the paper refers to the Italian and Spanish innovation policies. Both the countries are characterised by regional policies that are implemented following different targets and means with respect to the national ones. Italian policies initiated at the sub-national level are generally characterised by a lower public contribution that those at the central level. The former are largely targeted to SMEs and aimed to support less formalised innovation activities than the latter (Cefis and Evangelista, 2007; Barbieri et al., 2010). Although with differences, the same occurs in Spain (Garcia-Quevedo and Afcha-Chávez, 2009; Afcha-Chávez, 2011).

The empirical investigation of the additionality brought about by innovation policies in these two contexts is not new. Several studies have addressed it. ${ }^{6}$ However, all these studies do not lead to unambiguous results and rather often provide us with conflicting ones. Furthermore, proper comparisons - even among the studies that are focused on

\footnotetext{
${ }^{6}$ For an extensive review of these works, see Marzucchi (2012).
} 
the same country/programme - are not allowed, due to the differences in the considered effects and time-spans, as well as in employed data and methodologies.

Some general insights can only be drawn about the input additionality of the overall system of policy of the two countries. The evidence (Parisi and Sembenelli, 2003; Cefis and Evangelista, 2007; Cerulli and Potì, 2008; González and Pazó, 2008; Garcia-Quevedo and Afcha-Chávez, 2009; Hall et al. 2009) points to the general presence of positive effects of the policy on the firms' investments in R\&D, even if with some differences. In Italy, this result shows several specificities, depending on the kind of policy-instrument (for example, direct grants vs. tax incentives) and funding schemes (for example, those named FAR/FSRA vs. FIT) (Barbieri et al., 2010; Cerulli and Potì, 2010; De Blasio et al., 2011; Carboni, 2011). In Spain, the evidence of input additionality finds an exception in the case of regional policies, which are found to be ineffective in stimulating private investment in R\&D (Garcia-Quevedo and Afcha-Chávez, 2009).

As for the other additionality dimensions, a comparison between Italian and Spanish public interventions is hardly possible. Some evidence on the output additionality, although mixed, is available for the Italian policies only (Cefis and Evangelista, 2007; Cerulli and Potì, 2008, 2010; Merito et al. 2010; Colombo et al., 2011). As for the behavioural additionality, the only available investigations are mainly focused on the capacity of Spanish policy programmes to stimulate funded firms' interactions with other companies and research organisations (Busom and Fernández-Ribas, 2008; Fernández-Ribas and Shapira, 2009; Magro et al., 2010; Afcha-Chávez, 2011).

All in all, the picture emerging from the review of the extant literature is partial. For this reason, while representing a test of our methodology, the empirical application will also fill a knowledge-gap about the effectiveness of innovation policies in these two countries.

\subsection{Econometric strategy}

The econometric estimation of the additionality of innovation policies is based on what is called the "Average Treatment effect on the Treated" (ATT). Let us consider the policy as a treatment to "cure" the failures faced by firms, whose status is denoted by $D(D=1$ : treated; $D=0$ : untreated). If we denote its outcome, in the presence and absence of the treatment (policy), with $Y_{1}$ and $Y_{0}$, respectively, the ATT can be defined as:

$$
A T T=E\left(Y_{1}-Y_{0} \mid D=1\right)=E\left(Y_{1} \mid D=1\right)-E\left(Y_{0} \mid D=1\right)
$$

In Eq.(1), $E\left(Y_{1} \mid D=1\right)$ can be estimated with the average outcome of the treated firms. $E\left(Y_{0} \mid D=1\right)$, instead, cannot be observed. For the treated firms, it is not possible to detect the outcome that would have been reached in absence of the public funding. Accordingly, a suitable counter-factual of non-funded firms has to be chosen. Given the non-randomised nature of the policy support, it is necessary to take into account that 
treated and non-treated firms can be systematically different. On the one hand, some self-selection mechanisms could be in place. On the other hand, policy-makers can deliberately select recipients with certain characteristics, with either a "picking the winner" or a "aiding the poor" strategy (Cerulli, 2010). Estimating the counterfactual with the simple average outcome of the non-participants to the policy would thus imply a selection bias.

In order to control for this selection bias (on observables), we can use the "Propensity Score Matching" (PSM) estimation of the ATT (Rosenbaum and Rubin, 1983). This is essentially aimed at pairing treated firms with "twin" non-treated ones, so that the difference in the outcome is only due to the treatment. More specifically, PSM reduces the dimension of conditioning, matching funded firms with non-funded ones on the basis of their propensity score $(\operatorname{Pr}(D=1 \mid X)$ or $P(X))$. This represents the probability of being treated, given a set of covariates, $X$. In so doing, the PSM estimation of the ATT is given by ${ }^{7}$ :

$$
A T T_{P S M}=E_{P(X) \mid D=1}\left\{E\left[Y_{1} \mid D=1, P(X)\right]-E\left[Y_{0} \mid D=0, P(X)\right]\right\}
$$

In operational terms, the PSM estimation of the ATT is obtained by applying the multistep protocol proposed by Caliendo and Kopeinig (2008). At first, the propensity score is estimated with a probit model, which includes as covariates all the variables that are expected to affect the outcome and the treatment status. As a second step, a set of different matching algorithms is chosen. These basically differ in the way non-treated firms to be used as matches are selected and weighted. The use of more matching procedures provides us information on the stability and reliability of the emerging evidences. In particular, three types of algorithms developed in the literature (e.g. Becker and Ichino, 2004; Cameron and Trivedi, 2005; Smith and Todd, 2005; Caliendo and Kopeinig, 2008) are implemented: 5 nearest neighbours (5NN), calliper and kernel. ${ }^{8}$

The third step of the estimation protocol consists of imposing the common support condition to the matching algorithms. In what follows a "minima-maxima comparison" is applied. In addition to this, a 5\% "trim" is also imposed to the $5 \mathrm{NN}$ algorithm (Leuven and Sianesi, 2003; Caliendo and Kopeinig, 2008).

Finally, the quality of the matching is assessed. This is done by comparing the situation after and before the matching, to check that treated firms and matched controls are correctly aligned with respect to the vector of covariates, $X$. Four tests are employed: a

\footnotetext{
${ }^{7}$ This relies on two important assumptions (i.e. the conditional independence assumption, CIA, and the stable unit-treatment value assumption, SUTVA) and on the common support condition. See, among the others, Rubin (1986), Cameron and Trivedi (2005), Smith and Todd (2005), Caliendo and Kopeinig, (2008).

${ }^{8}$ Caliper matching is implemented with a maximum tolerance of 0.02 and kernel matching by using a Epanechnikov kernel function.
} 
regression-based $t$-test on differences in the covariates means, a loglikelihood ratio test; a pseudo $R^{2}$ test; a standardised bias test (Caliendo and Kopeinig, 2008).

\subsection{Dataset, variables and indicators}

\subsubsection{Dataset}

The empirical application of the paper employs data coming from the fourth wave of the Community Innovation Survey (CIS4) (2002-2004). As all the CIS waves, this is based on a harmonized questionnaire which is the same for all the European countries, thus allowing for comparable analyses.

The two working datasets originally consisted of 18,946 observations for Spain and 21,854 for Italy. Nevertheless, in order to provide a proper additionality evaluation of the regional and national policy interventions, their size has been reduced. Firstly, the analysis is limited to manufacturing firms. Secondly, in order to have the complete range of variables for all the observations, firms with unexpected missing values and firms that had not to fill the entire questionnaire ${ }^{9}$ are dropped. Finally, to provide a proper additionality evaluation of the regional (national) policies, the working datasets are limited to have: among the treated units, only firms that obtained a regional (national) funding; among the control units, only firms that did not receive any type of public support.

\subsubsection{Variables}

The first set of variables that we need for our econometric approach should account for the firm's treatment status. To this purpose, we considered whether the firm received some funding by the regional or local (FUNLOC), the national (FUNGMT) or the European (FUNEU) levels of government. Furthermore, we looked at whether the European support was granted within the $5^{\text {th }}$ or $6^{\text {th }}$ European Framework Programme for Research and Technical Development (FUNRTD). These dummy variables allow us to identify, on the one hand, those firms which were supported by regional or national funding schemes, on the other hand, those that were not funded at all.

The second set of variables refers to the covariates, $X$, to be included in the probit estimation of the propensity score specification (see Tab. A1 in the Appendix). These are identified by drawing on, and extending, recent studies which use a similar methodology (e.g. Czarnitki and Licht, 2006; Busom and Fernández-Ribas, 2008). ${ }^{10}$

\footnotetext{
9 Those companies that in the period 2002-2004 did not introduce any product or process innovation and did not carry out any innovation activities.

${ }^{10}$ For a deeper discussion of the chosen covariates, and of their expected sign in the probit estimation, see Marzucchi (2012). Considering the characteristics and the rationale of the econometric method here employed (see Section 4.1), the covariates used to estimate the propensity score essentially represent the observable characteristics we control for. Hence, these can be considered, in a sense, as analogous to the control variables included in the specification of a standard parametric regression model. As FUNLOC and FUNGMT refer to the 2002-2004 period, to avoid endogeneity problems, whenever possible, the propensity scores specification
} 
Firstly, the size of the firms and their economic sector are controlled through the logarithm of their turnover (In_TURNO2) and a set of size- (SMALL, MEDIUM and LARGE) and sector-dummies $\left(S E C_{-} D A-S E C_{-} D N\right)^{11}$. The firm's belonging to a business group $(G P)$, its eventual affiliation to a multinational corporation (MNCGROUP), and its engagement in foreign markets (EXPORT) are also considered.

Three other aspects are considered to explain the firms' participation in the investigated policy schemes: their engagement in R\&D, their financial constraints, and their external information sources. As for the first one, RDENG and RDCONT captures whether the firm engages in $R \& D$, and whether it does it in a continuous way, respectively. As for the second one, HFENT1, HFENT2, and HFENT3 are three dummies which capture whether the firm faces a "nil or low", "medium" or "high" lack of internal funding, respectively. Similarly HFOUT1, HFOUT2, and HFOUT3, capture whether the firm faces a "nil or low", "medium" or "high" problem in accessing to external funding, respectively. Finally, three dummies (SMGT1, SGMT2, and SGMT3) indicate the relevance ("nil or low", "medium", "high") of the governmental sources of information for the firm's innovative activities. Similarly, other three dummies indicate the relevance of the information coming from professionals and industry associations (SPRO1, SPRO2, SPRO3). ${ }^{12}$

The last set of variables that we consider is that of the outcome variables ${ }^{13}$ for capturing input, output and behavioural additionality. As for the input additionality, 2 variables are considered, that is: (i) the expenditure in intramural R\&D, in year 2004 (RDEXP); (ii) the intensity of the intramural R\&D investment (RDINT) on the turnover, in year 2004. As for the output dimension, 6 outcome variables are considered: (i) a dummy for product innovation (PRODINNO); (ii) a dummy for process innovation (PROCINNO); (iii) the percentage of turnover in year 2004, due to product innovations introduced in 2002-2004 that were new to the market (TURNMAR); (iv) the percentage of turnover in year 2004, due to product innovations introduced in 2002-2004 that were new to the firm (TURNIN); (v) the sum of TURNIN and TURNMAR (i.e. TURNINNO) ${ }^{14}$; (vi) a dummy for the presence of eventual patent applications (PROPAT). Concerning the behavioural dimension, two types of impact are considered with 5 further dummies. On the one side, the internal behavioural additionality of the policies is addressed by considering, with the dummy TRAINENG, whether firms are induced to upgrade employees' competencies

includes variables referred to the first year of the period (2002). This can be done for $\ln$-TURN02, SMALL, $M E D I U M$ and LARGE.

${ }^{11}$ Italian firms belonging to NACE rev. 1.119 (i.e. secDC in the CIS4 sectoral classification), 20 (belonging to sec20-21) and 23 (belonging to secDF-DG) are dropped from the working sample: for these sectors the anonymisation process, carried out by the Italian National Statistical Institute, resulted in the aggregation of medium and large firms into a unique dimensional class. Firms belonging to NACE rev. 1.130 (belonging to secDL) are drooped too, as for these the anonymisation process resulted in the aggregation of small, medium and large firms into a unique dimensional class.

${ }^{12}$ LARGE, HFENT1, HFOUT1, SGMT1, SPRO1, SEC27 (i.e. NACE rev 1.1 sector 27) are used as reference terms in the probit estimation of the propensity score.

${ }^{13}$ Unless differently reported, the variables defined below refer to the period 2002-2004.

${ }^{14}$ TURNMAR, TURNIN and TURNINNO are rescaled from 0 to 1. 
through formal training programmes, in order to carry on the publicly funded innovation activities. On the other hand, the external behavioural additionality of the policy is captured by 4 dummy variables, which capture whether the policies enhance the beneficiaries' networking - COOPFIRM and COOPORG ${ }^{15}$ - and interactions INFOFIRM and INFOORG ${ }^{16}$ - with other firms and research organisations, respectively.

\subsubsection{Indicators for the multi-additionality and multi-level analysis}

As has been illustrated in Section 4.1, the additionality of the investigated policy schemes is revealed by the significance, sign and size of the ATT with respect to the three groups of outcome variables capturing the input ( 2 variables), the output (6 variables) and the behavioural (5 variables) dimensions. Whereas the analysis of the ATTs can be used to look at the depth of the policy effects, simple indicators created upon the ATTs themselves can be used to investigate the multi-dimensional and multilevel aspects we have illustrated in Sections 2 and 3.

As for the multi-dimensionality of innovation policies, the identification of the relevant scenario - out of the 5 described in Section 2 - will be carried out in two steps. The first step is aimed at defining, for each type of intervention (regional and national, Italian and Spanish), an indicator of how wide is the effect of the policy across the different aspects (outcome variables) of a given additionality dimension (i.e. input, output or behavioural). For each additionality dimension, this is calculated by attaching value +1 , to positive and significant effects, -1 , to negative and significant effects, and 0 to non significant effects. Summing up these values, and dividing by the number of aspects (outcome variables) of each dimension, gives us an indicator which ranges between +1 and -1 . The rationale of this indicator is the following. Having additionality (of any size) on more aspects makes the policy more extensively additional along a certain dimension, possibly to the maximum extent (+1). Conversely, in calculating the additionality extent of a certain dimension, having crowding-out on some aspects

\footnotetext{
15 COOPFIRM is "exploded" in different dummies, capturing cooperation agreements with national (COOPGPNAT) and foreign firms belonging to the same group (COOPGPFOR); national (COOPSUPNAT) and foreign suppliers (COOPSUPFOR); national (COOPCUSNAT) and foreign customers (COOPCUSFOR); national (COOPCOMNAT) and foreign competitors (COOPCOMFOR). Similarly COOPORG is further specified to capture the cooperation with: national (COOPINSNAT) and foreign private R\&D institutes and commercial labs (COOPINSFOR); national (COOPUNINAT) and foreign universities (COOPUNIFOR); national (COOPPUBNAT) and foreign governmental agencies or public research institutes (COOPPUBFOR). However, the $A T T$ estimations for these specific types of cooperation are not discussed here and provided in the Appendix.

${ }^{16}$ These dummies are created from the four-point likert scales, included in the CIS4 dataset, that indicate the importance of different sources of information for the firm's innovation activities. The dummies take value 1 if the relevance of the information is "medium" or "high". INFOFIRM captures information coming from suppliers (INFOSUP), customers (INFOCUS) and competitors (INFOCOM). INFOORG includes information sourcing from universities (INFOUNI) and private research institutes (INFOINS). Still, the ATT estimations for these specific types of information sourcing are not discussed and provided in the Appendix.
} 
counterbalances the fact of having additionality on some others, or even fully dominates the dimension $(-1) \cdot{ }^{17}$

The second step of the analysis will look at the combination of these additionality indicators by dimension and calculate their average to determine whether a certain policy shows, as illustrated in Section 2: full multi-dimensionality, bi- or monodimensionality, rather than partial or full, cross-dimensional crowding-out.

As for the multi-level additionality of the policy, in order to ascertain which is the most relevant characterization - out of the 4 described in Section 3 - we proceed also in two steps. First of all, for each additionality dimension (i.e. input, output and behavioural) we count the number of cases in which the ATT of a certain outcome variable is significantly positive at both the regional and national level and, then, we divide by the number of outcome variables. For each additionality dimension, this gives us an indicator - ranging between 0 and 1 - that can be used to grasp the extent (or degree) to which the regional and national innovation policies show full, cross-level additionality. Mutatis mutandis, with a similar procedure - that is, calculating the average number of cases in which, for each dimension, we have additionality or crowding-out at only one of the two levels, and crowding-out at both levels - we can have an indication of what we called, respectively: partial cross-level additionality; partial cross-level crowding-out; full, cross-level crowding-out. In synthesis, for each dimension we are able to have a measurement of the four cross-level characterizations of Section 3 and see which is the most relevant.

In the second step, we calculate the average, across the three dimensions (input, output and behaviour), for each of these four indicators, in order to have for each of them a country-level specification. In other words, we can have an indication, again on scale between 0 and 1 , of the extent to which the relevant country displays, overall, one of the same specifications (that is, full, cross-level additionality; partial cross-level additionality; partial cross-level crowding-out; full, cross-level crowding-out).

As far as the last piece of our analysis is concerned, the total cross-level additionality that innovation policies show in a certain country can be investigated by amending the procedure to calculate the indicators we described above to analyse their multidimensionality. More precisely, we simply need to re-run the first step of the relative procedure, by counting and averaging up algebraically all the effects that, along a certain dimension, have been brought about by both regional and national policies. By combining these additionality indicators by dimension and calculating their average we can determine whether a certain policy-system shows - this time with a partial crosslevel specification: full multi-dimensionality, bi- or mono-dimensionality, rather than partial or full, cross-dimensional crowding-out (see Section 2).

\footnotetext{
${ }^{17}$ Values of this indicator close to zero could be equally due to compensating aspects or to non-significant ones, and would require careful inspection at the level of the single aspects (outcome variables).
} 


\section{Results}

In what follows, we present the evidence emerging from our empirical investigation. Firstly, we comment on the ATT results emerging from the PSM estimation and look at the intensity of the additionality of the investigated policies. Second, we examine the extension of the ATT results and consider the multi-dimensional and multi-level nature of the policy additionality.

\subsection{The additionality of Italian policies}

Looking at Table 1, regional and national policies appear to have quite a different impact on the investigated dimensions. Starting with the regional ones, the absence of input additionality is a first important result. Consistently with what other empirical investigations already argued, this is possibly explained by their greater attention for small scale innovation projects, whose activities have a more exploitative than explorative nature.

In terms of output additionality, regional policies give the impression of inducing Italian firms to adopt a sort of shift in their innovation outcomes. With respect to similar nonfunded firms, funded ones are more likely (from $+11.1 \%$ to $+13.3 \%$, depending on the adopted matching procedure) to achieve a process innovation, but less likely to introduce a new or improved product (from $-4.7 \%$ to $-6.3 \%$ ). This lower propensity is also reflected in the proportion of turnover due to incremental product innovations, which is found to be negatively affected by the public support (from $-1.6 \%$ to $-2.5 \%$ ). This is an interesting result, which suggests that regional policies in the country help firms deepening, rather than reversing, the innovative patterns that Italian firms show in their local systems of production (industrial districts, in particular). Their sectoral specialization (for example, in textiles, ceramics, machinery, and the like) actually rely more on a process rather than a product kind of innovation (Boix and Galletto, 2009).

The evidence about the behavioural additionality of regional policies is in general quite gloomy. The likelihood of being engaged in training programmes is lower for supported firms than for similar non-funded companies (from $-4.3 \%$ to $-5.2 \%$ ). In their cooperation agreements, funded firms are generally not statistically different from nonfunded ones ${ }^{18}$. Funded firms are less engaged in information sourcing from other companies (form $-4.3 \%$ to $-6.5 \%$ ). All in all, not only seem regional policies unable to tackle system failures in the RIS. But they even appear to pose firms further public failures, which diminish their pre-policy innovative behaviours. The only relevant exception is represented by their positive effect on the firms' propensity to acquire relevant information from research organisations (from $+9.5 \%$ to $+10.1 \%$ ). ${ }^{19}$ Given the

\footnotetext{
${ }^{18}$ Funded companies are less likely to be engaged in collaboration with national competitors (see Tab. A2 in the Appendix).

${ }^{19}$ Looking at the different types of information sourcing (see Tab. A2 in the Appendix) it is possible to notice the higher propensity of funded firms to acquire relevant knowledge from private R\&D institutes. On the contrary, supported companies are less likely to obtain relevant information from universities and suppliers.
} 
role that this information has for innovation at the regional level (Marzucchi et al. 2012), although somehow isolated, such a result should be welcomed as an extremely positive one.

Looking at the national interventions (Table 1), unlike the regional ones, Italian policies do show a relevant input additionality. In terms of R\&D investments, the policy effect on the supported firms ranges from $+427,914.1$ Euros to $+447,613.6$ Euros (still depending on the matching procedure). This is reflected in the increased intensity of firms' R\&D investment, from $+0.6 \%$ to $+0.7 \%$. National policies in Italy are actually able to tackle the most typical market failure in innovation. However, the higher investment in formal innovation activities induced by the policy does not translate into an increased capacity to introduce product and patentable innovations. Funded firms, with respect to similar non-supported ones, only have a higher propensity to introduce new or improved processes (from $+8.3 \%$ to $+9.6 \%$ ). But no significant effect is found for all the other output additionality indicators. Once more, the production structure of the country can provide an explanation for this result. Furthermore, the same result suggests that public interventions devised at the central level are not able to display their effect along the whole liner model in innovation, and remain somehow blocked at the input level.

To be sure, the bottleneck appears located even more upward, when we consider the results in terms of behavioural additionality. Italian national policies are found to increase funded firms' propensity to engage in R\&D cooperation with both other firms (from $+4.9 \%$ to $+5.2 \%$ ) and, to a larger extent, with research partners (from $+10.3 \%$ to $11.6 \%)^{20}$. Furthermore, the policy induces increased information sourcing from universities and private R\&D institutes (from $+10.8 \%$ to $+11.3 \%)^{21}$. Still, something misses for the policy to have an actual innovation impact. Its lack of effects on the training of the treated firms should be considered in understanding what is actually missing.

\footnotetext{
${ }^{20}$ As it emerges from Tab. A3 in the Appendix, Italian national policies enhances the propensity to cooperate with national and global suppliers, national private R\&D institutes and national universities.

${ }^{21}$ See Tab. A3 in the Appendix for a more detailed analysis.
} 
Tab. 1 Additionality of Italian policies

\begin{tabular}{|c|c|c|c|c|c|c|c|c|}
\hline \multirow[t]{2}{*}{ Regional policies } & \multicolumn{2}{|c|}{$5 \mathrm{NN}$} & \multicolumn{2}{|c|}{ Caliper } & \multicolumn{2}{|c|}{ Kernel } & \multicolumn{2}{|c|}{ 5NN Trim } \\
\hline & ATT & S.E. & ATT & S.E. & ATT & S.E. & ATT & S.E. \\
\hline \multicolumn{9}{|l|}{ Input add. } \\
\hline RDEXP & 42295.320 & 67483.270 & 43382.720 & 67180.760 & 23791.990 & 47706.630 & 45794.740 & 71086.020 \\
\hline RDINT & 0.003 & 0.002 & 0.003 & 0.002 & 0.002 & 0.002 & 0.003 & 0.002 \\
\hline \multicolumn{9}{|l|}{ Output add. } \\
\hline PRODINNO & $-0.047 *$ & 0.028 & $-0.058 * *$ & 0.029 & $-0.050 * *$ & 0.023 & $-0.063 * *$ & 0.031 \\
\hline PROCINNO & $0.122^{* * *}$ & 0.031 & $0.118^{* * *}$ & 0.029 & $0.111^{* * *}$ & 0.023 & $0.133^{* * *}$ & 0.033 \\
\hline TURNMAR & 0.002 & 0.013 & -0.003 & 0.012 & -0.002 & 0.010 & 0.002 & 0.013 \\
\hline TURNIN & $-0.021 * *$ & 0.010 & $-0.025^{* *}$ & 0.010 & $-0.016^{*}$ & 0.009 & $-0.022 *$ & 0.012 \\
\hline TURNINO & -0.019 & 0.017 & $-0.028 *$ & 0.016 & -0.017 & 0.013 & -0.019 & 0.015 \\
\hline PROPAT & -0.023 & 0.026 & -0.019 & 0.025 & -0.007 & 0.020 & -0.021 & 0.025 \\
\hline \multicolumn{9}{|l|}{ Behavioural add. } \\
\hline TRAINENG & $-0.046 *$ & 0.025 & $-0.046^{*}$ & 0.027 & $-0.043 *$ & 0.022 & $-0.052 *$ & 0.027 \\
\hline COOPFIRM & -0.028 & 0.020 & -0.028 & 0.018 & -0.015 & 0.013 & $-0.040 * *$ & 0.019 \\
\hline COOPORG & -0.019 & 0.016 & -0.019 & 0.016 & -0.012 & 0.013 & $-0.028 *$ & 0.017 \\
\hline INFOFIRM & $-0.059 * * *$ & 0.022 & $-0.065 * * *$ & 0.024 & $-0.043 * *$ & 0.020 & $-0.065 * * *$ & 0.023 \\
\hline INFOORG & $0.097^{* * *}$ & 0.029 & $0.101^{* * *}$ & 0.028 & $0.097^{* * *}$ & 0.027 & $0.095^{* * *}$ & 0.031 \\
\hline$N$ treat. on support & \multicolumn{2}{|c|}{598} & \multicolumn{2}{|c|}{598} & \multicolumn{2}{|c|}{598} & \multicolumn{2}{|c|}{570} \\
\hline$N$ treated total & \multicolumn{2}{|c|}{599} & \multicolumn{2}{|c|}{599} & \multicolumn{2}{|c|}{599} & \multicolumn{2}{|c|}{599} \\
\hline$N$ non treated & \multicolumn{2}{|c|}{1407} & \multicolumn{2}{|c|}{1407} & \multicolumn{2}{|c|}{1407} & \multicolumn{2}{|c|}{1407} \\
\hline
\end{tabular}

\begin{tabular}{|c|c|c|c|c|c|c|c|c|}
\hline \multirow[t]{2}{*}{ National policies } & \multicolumn{2}{|c|}{$5 \mathrm{NN}$} & \multicolumn{2}{|c|}{ Caliper } & \multicolumn{2}{|c|}{ Kernel } & \multicolumn{2}{|c|}{ 5NN Trim } \\
\hline & ATT & S.E. & ATT & S.E. & ATT & S.E. & ATT & S.E. \\
\hline \multicolumn{9}{|l|}{ Input add. } \\
\hline RDEXP & 429066.1 * & 238670.7 & $427914.1^{*}$ & 228623.0 & $447613.6^{* *}$ & 218544.8 & 313001 & 261069.2 \\
\hline RDINT & $0.007^{* *}$ & 0.003 & $0.007^{* *}$ & 0.003 & $0.006^{* *}$ & 0.003 & $0.007^{* *}$ & 0.003 \\
\hline \multicolumn{9}{|l|}{ Output add. } \\
\hline PRODINNO & 0.004 & 0.034 & 0.005 & 0.034 & 0.006 & 0.025 & 0.000 & 0.033 \\
\hline PROCINNO & 0.086 ** & 0.036 & $0.086^{* *}$ & 0.035 & $0.096 * * *$ & 0.027 & $0.083^{* *}$ & 0.037 \\
\hline TURNMAR & -0.002 & 0.013 & -0.001 & 0.015 & -0.005 & 0.010 & -0.002 & 0.013 \\
\hline TURNIN & 0.016 & 0.012 & 0.016 & 0.014 & 0.013 & 0.011 & 0.015 & 0.012 \\
\hline TURNINO & 0.014 & 0.018 & 0.014 & 0.017 & 0.007 & 0.014 & 0.013 & 0.018 \\
\hline PROPAT & 0.047 & 0.030 & 0.048 & 0.031 & $0.061^{* * *}$ & 0.024 & 0.041 & 0.030 \\
\hline \multicolumn{9}{|l|}{ Behavioural add. } \\
\hline TRAINENG & 0.007 & 0.032 & 0.005 & 0.033 & 0.010 & 0.029 & -0.002 & 0.032 \\
\hline COOPFIRM & $0.051^{* *}$ & 0.026 & 0.050 * & 0.026 & $0.052^{* * *}$ & 0.019 & $0.049^{* *}$ & 0.023 \\
\hline COOPORG & $0.104^{* * *}$ & 0.027 & $0.103^{* * *}$ & 0.025 & $0.116^{* * *}$ & 0.022 & $0.108^{* * *}$ & 0.024 \\
\hline INFOFIRM & -0.010 & 0.025 & -0.009 & 0.027 & -0.015 & 0.022 & -0.014 & 0.026 \\
\hline INFOORG & $0.113^{* * *}$ & 0.035 & $0.112^{* * *}$ & 0.036 & $0.108^{* * *}$ & 0.027 & $0.111^{* * *}$ & 0.038 \\
\hline$N$ treat. on support & \multicolumn{2}{|c|}{433} & \multicolumn{2}{|c|}{433} & \multicolumn{2}{|c|}{433} & \multicolumn{2}{|c|}{417} \\
\hline$N$ treated total & \multicolumn{2}{|c|}{438} & \multicolumn{2}{|c|}{438} & \multicolumn{2}{|c|}{438} & \multicolumn{2}{|c|}{438} \\
\hline$N$ non treated & \multicolumn{2}{|c|}{1407} & \multicolumn{2}{|c|}{1407} & \multicolumn{2}{|c|}{1407} & \multicolumn{2}{|c|}{1407} \\
\hline
\end{tabular}




\subsection{The additionality of Spanish policies}

Table 2 shows the additionality of the Spanish policies at the regional and national level.

As much as in Italy, also in Spain regional policies lack of significant effects on the private investment in R\&D. Similar arguments - in terms of size and novelty of the finance projects - can be put forward, still consistently with the extant literature.

In this case, however, unlike in the Italian one, regional support schemes enhance the probability to introduce product innovations (from $+3.8 \%$ to $+3.9 \%$ ), in particular radical and commercially valuable ones. With respect to similar non-funded firms, funded ones are characterised by a higher percentage of turnover due to radical product innovations (from $+1.5 \%$ to $+1.8 \%$ ). Finally, this higher innovation performance is coupled with a higher propensity to file patent applications (from $+6.0 \%$ to $+7.2 \%$ ). In brief, Spanish regional policies appear able to induce local firms to adopt a higher level of innovative outcomes than the Italian ones. Furthermore, unlike in Italy, this radicalproduct additionality does not occur at the expenses of other lower grade innovative patterns (e.g., process and incremental like).

The presence of this output additionality, in the absence of the input one, might appear difficult to explain. An interpretation for it can be obtained by looking at the behavioural additionality of Spanish regional policies. On the one hand, they enhance the beneficiaries' learning process and increase the supported-firms' propensity to implement formal training programmes (from $+4.8 \%$ to $+6.1 \%$ ). On the other hand, they also increase the firms' attitude to cooperate, with both other firms (from $+7.3 \%$ to $+7.5 \%$ ) and research organisations (from $+9.6 \%$ to $+10.3 \%)^{22}$, and to acquire relevant knowledge from research partners (from $+10.5 \%$ to $12.1 \%)^{23}$. On this basis, we could argue that regional policies help firms to innovate more, by helping them to resort more to an open innovation mode, in which external (rather than internally produced knowledge) is a crucial innovative input.

Looking at the national Spanish policies (Table 2), as for the Italian ones, their input additionality is evident. Innovation support schemes devised at the central level are found to stimulate an additional investment in intramural R\&D (from + 354,036.2 Euros to $+371,922.7$ Euros, depending on the matching procedure). However, unlike we found in Italy, a similar positive effect is not found for the intensity of the R\&D investment. In other words, it seems like the national policies are not able to increase the relative incidence of R\&D investments on the business scale of the treated firms.

In terms of output additionality, national policies also do their job. With respect to similar non funded companies, supported firms are characterised by a higher

\footnotetext{
${ }^{22}$ In particular, Spanish regional interventions increase funded firms' propensity to cooperate with a broad range of national partners (i.e. firms belonging to the same group, suppliers, competitors, private R\&D institutes, universities and public research organisations) (See Tab. A4 in Appendix).

${ }^{23}$ From both private R\&D institutes and universities (See Tab. A4 in the Appendix).
} 
percentage of turnover due to radical product innovations (from $+3.7 \%$ to $+4.0 \%$ ) and a higher propensity to file patent applications (from $+5.9 \%$ to $+7.3 \%$ ). Unlike in Italy, national interventions impact on the most valuable kind of innovative outcomes. Furthermore, this difference emerges even if the two countries have not radically dissimilar productions structures.

Given the important impact that national policies show in terms of input, this result suggests their capacity to spread their effects along the innovation chain. This is also supported by the relevant number of behavioural changes induced by the public support at the same level. National policies enhance the propensity to cooperate with both research organisations (from $+10.5 \%$ to $+11.3 \%$ ) and other firms (from $+8.1 \%$ to $+8.6 \%)^{24}$. Treated firms show a higher propensity to acquire relevant information from both other firms (from $+5.0 \%$ to $+7.0 \%$ ) and research organisations (from $+10.0 \%$ to $+11.6 \%)^{25}$. Last, but not least, funded firms are more likely to implement training programmes (from $+5.1 \%$ to $+6.0 \%$ ). This is a result which was missing from the companion evaluation in Italy and which thus reinforces our interpretation about the limited extent to which input additionality was accompanied by the output one in that context.

In synthesis, the two countries show a lot of differences in the effects that their innovation policies produce. ${ }^{26}$ As we suggest, some of these differences have to do with the different way in which the ATTs combine across the different additionality dimensions, and across the levels of government. This is an aspect that the analysis of the following two sections will try to illustrate in a more explicit way.

Tab. 2 Additionality of Spanish policies

\begin{tabular}{|c|c|c|c|c|c|c|c|c|}
\hline \multirow[t]{2}{*}{ Regional policies } & \multicolumn{2}{|c|}{$5 \mathrm{NN}$} & \multicolumn{2}{|c|}{ Caliper } & \multicolumn{2}{|c|}{ Kernel } & \multicolumn{2}{|c|}{ 5NN Trim } \\
\hline & ATT & S.E. & ATT & S.E. & ATT & S.E. & ATT & S.E. \\
\hline \multicolumn{9}{|l|}{ Input add. } \\
\hline RDEXP & -5305.556 & 34001.730 & -5352.441 & 34923.640 & 17351.620 & 20613.090 & -7059.569 & 35644.120 \\
\hline RDINT & 0.154 & 0.151 & 0.154 & 0.147 & 0.156 & 0.139 & 0.161 & 0.147 \\
\hline \multicolumn{9}{|l|}{ Output add. } \\
\hline PRODINNO & $0.038^{*}$ & 0.022 & $0.039 *$ & 0.023 & $0.039 *$ & 0.021 & 0.038 & 0.025 \\
\hline PROCINNO & 0.022 & 0.023 & 0.023 & 0.025 & $0.042 * *$ & 0.019 & 0.023 & 0.026 \\
\hline TURNMAR & $0.017^{*}$ & 0.009 & $0.017 *$ & 0.009 & $0.015^{* *}$ & 0.007 & $0.018 * *$ & 0.008 \\
\hline TURNIN & 0.002 & 0.014 & 0.001 & 0.013 & 0.001 & 0.011 & -0.001 & 0.013 \\
\hline
\end{tabular}

\footnotetext{
${ }^{24}$ From Tab. A5 in the Appendix, it is possible to notice a positive effect on firms' propensity to cooperate with national firms in the same group, national suppliers, national and foreign competitors. As for the cooperation with research organisations, national policies increase the propensity to cooperate with national public and private $R \& D$ institutes and national universities.

${ }^{25}$ In particular, from customers, private R\&D institutes and universities (See Tab. A5 in the Appendix).

${ }^{26}$ It should be stressed that, although not reported, the results of the tests (available upon request) largely support the quality of all the employed matching procedures of Tables 1 and 2 .
} 


\begin{tabular}{|c|c|c|c|c|c|c|c|c|}
\hline \multirow{2}{*}{$\begin{array}{l}\text { Regional policies } \\
\text { TURNINO }\end{array}$} & \multicolumn{2}{|c|}{$5 N N$} & \multicolumn{2}{|c|}{ Caliper } & \multicolumn{2}{|c|}{ Kernel } & \multicolumn{2}{|c|}{ 5NN Trim } \\
\hline & 0.019 & 0.016 & 0.019 & 0.014 & 0.016 & 0.013 & 0.017 & 0.015 \\
\hline PROPAT & $0.068 * * *$ & 0.020 & $0.068 * * *$ & 0.020 & $0.060 * * *$ & 0.016 & $0.072 * * *$ & 0.021 \\
\hline \multicolumn{9}{|l|}{ Behavioural add. } \\
\hline TRAINENG & $0.048^{* *}$ & 0.023 & $0.048^{* *}$ & 0.022 & $0.061^{* * *}$ & 0.018 & $0.048 * *$ & 0.024 \\
\hline COOPFIRM & $0.073^{* * *}$ & 0.021 & $0.075^{* * *}$ & 0.020 & $0.073^{* * *}$ & 0.015 & $0.073^{* * *}$ & 0.019 \\
\hline COOPORG & $0.099 * * *$ & 0.018 & $0.099 * * *$ & 0.016 & $0.103^{* * *}$ & 0.013 & $0.096^{* * *}$ & 0.017 \\
\hline INFOFIRM & 0.019 & 0.018 & 0.021 & 0.020 & 0.020 & 0.013 & 0.017 & 0.020 \\
\hline INFOORG & $0.105^{* * *}$ & 0.021 & $0.105^{* * *}$ & 0.022 & $0.121^{* * *}$ & 0.019 & $0.115^{* * *}$ & 0.023 \\
\hline$N$ treat. on support & \multicolumn{2}{|c|}{876} & \multicolumn{2}{|c|}{874} & \multicolumn{2}{|c|}{876} & \multicolumn{2}{|c|}{836} \\
\hline$N$ treated total & \multicolumn{2}{|c|}{879} & \multicolumn{2}{|c|}{879} & \multicolumn{2}{|c|}{879} & \multicolumn{2}{|c|}{879} \\
\hline$N$ non treated & \multicolumn{2}{|c|}{3231} & \multicolumn{2}{|c|}{3231} & \multicolumn{2}{|c|}{3231} & \multicolumn{2}{|c|}{3231} \\
\hline \multirow[t]{2}{*}{ National policies } & \multicolumn{2}{|c|}{$5 \mathrm{NN}$} & \multicolumn{2}{|c|}{ Caliper } & \multicolumn{2}{|c|}{ Kernel } & \multicolumn{2}{|c|}{ 5NN Trim } \\
\hline & ATT & S.E. & ATT & S.E. & ATT & S.E. & ATT & S.E. \\
\hline \multicolumn{9}{|l|}{ Input add. } \\
\hline RDEXP & $\begin{array}{c}367677.1 \\
* *\end{array}$ & 162523.3 & $371922.7^{* *}$ & 164501.7 & $359347.8^{* * *}$ & 132797.8 & 354036.2 ** & 156419.1 \\
\hline RDINT & 0.071 & 0.049 & 0.072 & 0.046 & 0.075 & 0.054 & 0.074 & 0.050 \\
\hline \multicolumn{9}{|l|}{ Output add. } \\
\hline PRODINNO & 0.001 & 0.027 & 0.001 & 0.028 & 0.014 & 0.022 & 0.015 & 0.030 \\
\hline PROCINNO & 0.022 & 0.030 & 0.026 & 0.028 & 0.037 & 0.023 & 0.012 & 0.029 \\
\hline TURNMAR & $0.037^{* * *}$ & 0.011 & $0.038^{* * *}$ & 0.012 & $0.040^{* * *}$ & 0.010 & $0.040 * * *$ & 0.011 \\
\hline TURNIN & -0.013 & 0.015 & -0.012 & 0.016 & -0.018 & 0.013 & -0.009 & 0.015 \\
\hline TURNINO & 0.024 & 0.019 & 0.026 & 0.018 & 0.022 & 0.015 & $0.032 *$ & 0.019 \\
\hline PROPAT & $0.059 * *$ & 0.025 & $0.062 * * *$ & 0.023 & $0.064^{* * *}$ & 0.020 & $0.073^{* * *}$ & 0.025 \\
\hline \multicolumn{9}{|l|}{ Behavioural add. } \\
\hline TRAINENG & $0.060 * *$ & 0.030 & $0.061^{* *}$ & 0.031 & $0.051 * *$ & 0.026 & $0.060 *$ & 0.032 \\
\hline COOPFIRM & $0.086^{* * *}$ & 0.026 & $0.086^{* * *}$ & 0.029 & $0.081^{* * *}$ & 0.020 & $0.081^{* * *}$ & 0.025 \\
\hline COOPORG & $0.111^{* * *}$ & 0.021 & $0.113^{* * *}$ & 0.023 & $0.110^{* * *}$ & 0.019 & $0.105^{* * *}$ & 0.023 \\
\hline INFOFIRM & $0.061^{* * *}$ & 0.024 & $0.061^{* * *}$ & 0.023 & $0.050^{* * *}$ & 0.018 & $0.070 * * *$ & 0.024 \\
\hline INFOORG & $0.100 * * *$ & 0.026 & $0.100^{* * *}$ & 0.028 & $0.116^{* * *}$ & 0.021 & $0.101^{* * *}$ & 0.028 \\
\hline$N$ treat. on support & \multicolumn{2}{|c|}{564} & \multicolumn{2}{|c|}{564} & 56 & & 53 & \\
\hline$N$ treated total & & & 56 & & 56 & & 56 & \\
\hline$N$ non treated & & & 323 & & 323 & & 323 & \\
\hline
\end{tabular}

$* * *, * *, *$ indicate a significance level of 1\%,5\%, 10\%. Standard errors are calculated with a 200replication bootstrap procedure.

\subsection{The multi-dimensional additionality of innovation policies}

As we have implicitly recognised in the previous two sections, in both the investigated countries, full multi-dimensionality is exclusive of the additionality of national policies (Figure 1). ${ }^{27}$ Both in Italy and Spain, the national policy schemes have a wide-spread impact on the innovation process of the targeted firms. In other words, they generally

27 The following analysis is based on the most used of the matching procedure in the PSM, that is the $5 \mathrm{NN}$. However, as well as those of the previous section, the results are robust across the other procedures. 
serve to cure, although to different extents, the whole array of failures that firms face in their innovation system.

The multi-dimensionality indicator for the national policies of the two countries yields very similar values: 0.59 in Italy and 0.61 in Spain. However, quite interestingly, Italian and Spanish national supporting schemes are characterised by different and somehow symmetric multi-dimensionality profiles. Diagrammatically, this is reflected by the quasi-perfect mirroring of the two correspondent rhomb (Figure 1). The number of aspects (outcome variables) along which the policy significantly adds something is maximum with respect to the input dimension, in Italy, and with respect to the behavioural one, in Spain. Conversely, the net additionality has approximately half of the value with respect to the behavioural dimension, in Italy, and with respect to the input one, in Spain. The higher net degree of the Spanish additionality at the output level also contributes to explain this multi-additionality comparison. Still, it is worthwhile investigating whether Italian and Spanish firms attach an opposite strategic value to their innovative inputs and behaviours in using a national policy support.

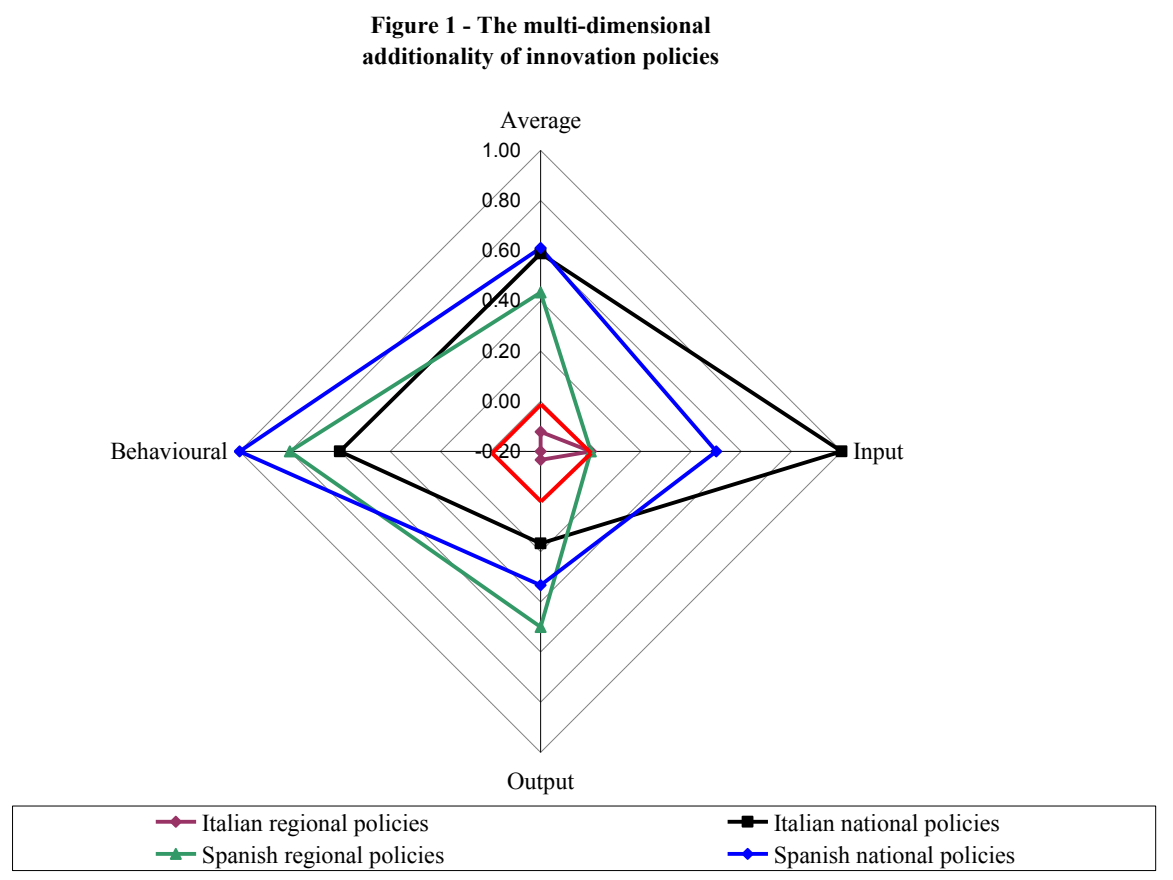

Regional innovation policies do not cover the whole spectrum of failures in both the countries, but with different characterisations. Italian regional policies show what we called full, cross-dimensional crowding-out. This emerges as the combination of small negative impacts, in terms of output and behavioural additionality, which the absence of any significant input additionality does not allow to compensate. In Figure 1, the relative contour is fully inscribed into the red-zero rhomb. Although, as we have seen in Section 5.1, some positive insights have emerged from the inspection of specific outcome variables, this result represents a serious concern about the effectiveness of local innovation policies in Italy. 
The "twin" policy scheme in Spain seems to work much better across the considered dimensions. The Spanish result suggests, like the Italian one, the general difficulty of regional innovation policies to stimulate additional $R \& D$ investments: the relative contour shares the correspondent vertex of the red-zero rhomb. However, the Spanish regional policies appear to have remarkable bi-dimensionality in terms of behavioural and output additionality. To be sure, the Spanish net-effect in terms of behavioural and, above all, output additionality shows how regional policies can get closer, or even forge ahead (in terms of output), national ones. In the case of Spanish regional policies, the multi-dimensionality indicator we have worked out has a value $(0.43)$ not that far away from that of the national ones (0.61). In this respect, it seems plausible that Spanish regional policies, by targeting (with success) the achievement of important behavioural changes, overcome the lack of input additionality and increase the capacity of funded firms to obtain more radical product innovations and patents (see also Tab. 2). Hence, at least with respect to this specific case, it seems that the lack of input additionality, per $s e$, does not completely hamper the effect of the public support on the outputs of the innovation process, especially when significant behavioural changes are stimulated by the policy.

\subsection{The multi-level additionality of innovation policies}

Figure 2 reports the cross-level characterization of the policy-additionality in Italy and Spain, following the taxonomy of Section 3.

The input dimension is the only one along which, in both countries, the unique possible cross-level pattern is of partial additionality, with only one effective policy level: the national one. This is the more so in Italy than in Spain. However, in both countries regional and national polices seem to follow a labour-division in this realm. This result can also be explained by the way in which the policy-systems are implemented in the two countries. Both in Italy and Spain, regional policies, when compared to national ones, are characterised by a lower public support and a higher attention to less formalised innovation activities (Cefis and Evangelista, 2007; Barbieri et al., 2010; Garcia-Quevedo and Afcha-Chávez, 2009; Afcha-Chávez, 2011). Hence, our result could also suggest that input additionality is not an automatic effect of the public support to firms' innovation activities. It rather emerges when policies are characterised by a sufficiently large scale and scope. 
Figure 2 - Multi-level additionality of innovation policies

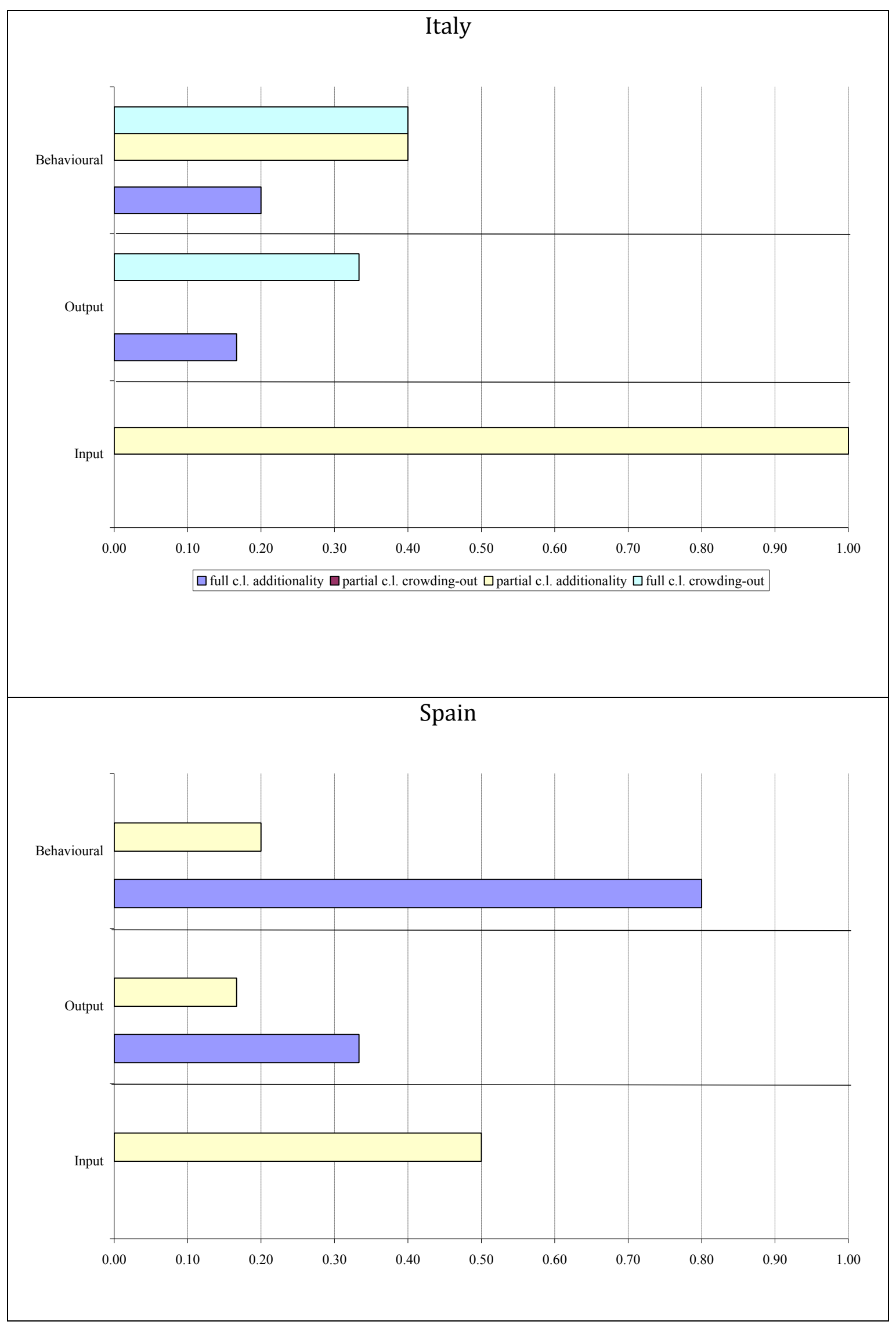


The output dimension is one along which a certain degree of full, cross-level additionality can be detected in both countries. However, this is as twice in Spain (0.33) than in Italy (0.17). Furthermore, in Italy this is more than counter-balanced by the evidence of full cross-level crowding-out. In a high number of cases (outcome variables) than those of full cross-level additionality, Italian regional and national policies have both a negative impact on the innovative output of the treated firms. This suggests that, overall, Italian policies expose firms to relevant public failures and actually decrease their innovativeness more extensively than they increase it. In Spain instead, a remarkable extent of full cross-level additionality is accompanied by a lower partial cross-level additionality. The number of cases in which the two-levels simultaneously add to the firms' innovative output is higher than that in which it occurs individually. Overall, the two levels of government show a higher capability to work complementary in spurring the firms' innovative outcomes in Spain than in Italy.

Coming to the behavioural dimension, Spain shows a similar picture than that of the output dimension, though with different degrees. Accompanied by a slightly higher partial cross-level additionality, the extent to which regional and national policies both add to the firms' innovative behaviours in Spain is nearly maximum ( 0.8 out of 1 ). The two policy levels look very effective in combining their efforts for solving the system failures from which innovation can be affected. The picture is quite the opposite in Italy, where this complementarity is limited to only one of the relevant aspects (outcome variables). In the majority of the cases, Italian national and regional policies subtract something from the pre-policy innovative behaviours of the treated firms, either alone or in combination. As well as the output dimension, the behavioural dimension appears one in which public failures are the net result of the public interventions in Italy. ${ }^{28}$

The resulting average picture is illustrated in Figure 3. Italy has a higher full cross-level crowding-out, and stays ahead Spain in partial cross-level additionality. On the contrary, Spain has a higher extent of full, cross-level additionality. On this basis, we can conclude that the multi-level system of policy has worked more extensively in Spain than in Italy.

\footnotetext{
${ }^{28}$ As can be seen in Tab. 1, Italian national policies outperform regional ones in terms of impact on firms' interactions. This might be due to two possible factors. On the one hand, a higher support, which can also take the form of explicit requirement, to collaborate with research organisations or (also through temporary consortia) with other firms. On the other hand, the larger scale, scope and aim of the projects funded by the Italian national policies (Cefis and Evangelista, 2007; Barbieri et al. 2010) might induce firms to look for necessary assets, both tangible and intangible, which are located outside their boundaries.
} 


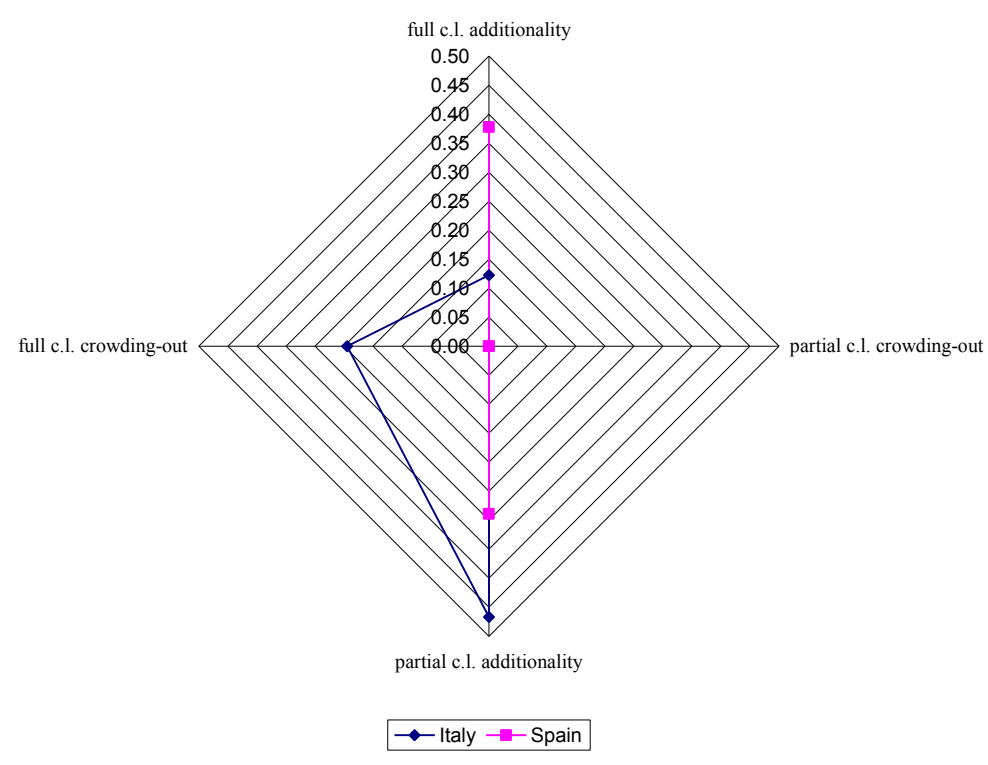

To conclude, let us consider the total cross-level additionality of the innovation policies. It should be noted that this analysis is substantially different from the "simple" crosslevel one of Figure 2 and 3. In that case, the two levels of government had been considered together providing they matched on the same aspect of the relevant dimension. In this case, their effects are pooled together along each dimension, irrespectively from their matching, but for their simple existence and with their actual sign. Figure 4 shows that, in terms of total cross-level effects, Spanish innovation policies exhibit full multi-dimensionality. With the same specification, instead, Italian ones appear only bi-dimensional in their additionality. In other words, in total terms, the considered innovation policies have more extensive additionality effects in Spain than in Italy.

When we considered the single additionality dimensions, Italian policies appear unable to obtain a total significant effect on the firms' innovative outputs. By pooling together all the effects that regional and national policies have along the relevant aspects of the output dimension, they simply cancel out. The convergence of regional and national support schemes appears to make the treated firms facing a picture of conflicting tradeoffs which, at the end, do not increase the firms' innovativeness. On the other hand, the partial cross-level additionality of the Italian policies is higher than the Spanish one in terms of input. All, in all, Italian policies displays a greater capacity than Spain in tackling the most standard of the market failures in innovation. Conversely, the set of regional and national interventions which significantly impact on the aspects of the firms' behavioural additionality (higher in Spain than Italy), suggests that Spanish policies have greater capacity of tackling system kind of failures. 


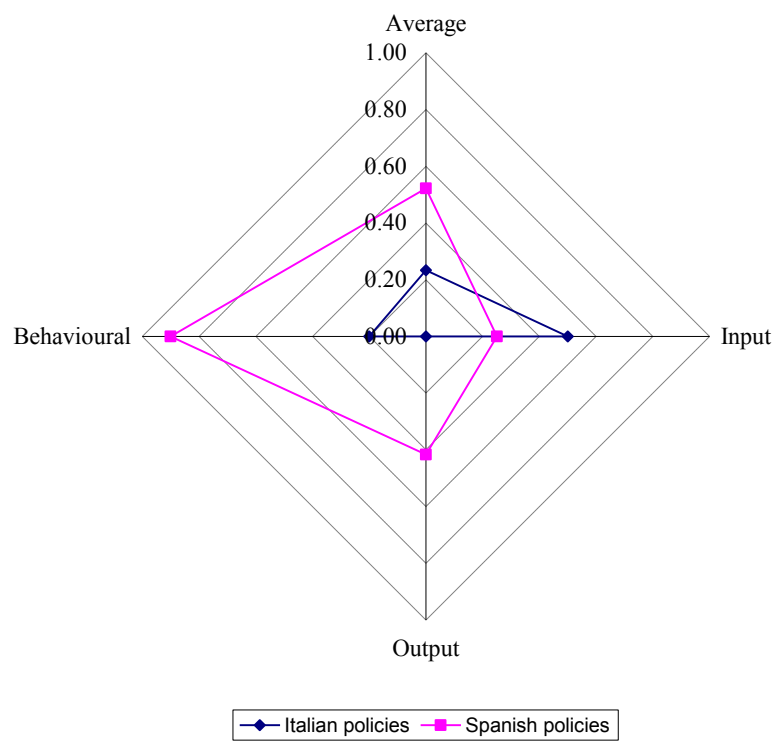

\section{Conclusions}

Evaluating the impact of innovation policies is a complex task. On the one hand, failures can have different nature and affect, not only the firms' innovative efforts and outcomes, but also their innovative behaviours. On the other hand, the public interventions to cure these failures are devised at different level of governments, by raising the issue of their possible combined effects. For these reasons, the evaluation needs to be multidimensional and cross-level.

In this paper we have shown that, looking for the additionality of innovation policies, this complex evaluation can be effectively undertaken. Furthermore, it can be carried out on a systematic basis, with the possibility of recovering the lack of comparability from which policy evaluations generally suffer. Using the Propensity Score Matching (PSM) estimation of the Average Treatment effect on the Treated, a multi-dimensional analysis can be carried out by looking at outcome variables pertaining to different realms. Their multi-level analysis is also possible, by using as treatment variables policy schemes initiated at different levels of government: in particular, regional and national. Finally, some simple indicators can be built up in order to express the results of these analyses in a synthetic way.

The empirical application we have carried out for Italy and Spain has served as a test for this complex evaluation procedure. Firstly, it has provided us with interesting results about the single dimensions along which additionality has been investigated, and about the single aspects which refer to each dimension. For example, consistently with previous evidence, regional policies do not show input additionality in the two countries: a result which appears explained by the nature of the innovative projects that regional policies target. However, unlike in Italy, Spanish regional policies have also 
remarkable output additionality impacts. The behavioural additionality that, again unlike in Italy, they show in this context can provide one explanation for that. ${ }^{29}$ Spanish regional policies stimulate firms' innovation by enabling them to rely more on external knowledge. This is an interesting piece of evidence, which contrasts the predictions of the standard linear innovation model.

Another illustrative result concerns the output additionality that national policies reveal in the two countries. In Italy, their impact is limited to process innovations, in Spain instead it reaches product innovations, even of radical nature. Given the relatively similar production structure of these two countries - and also their not very dissimilar, innovation profile - this result is somehow surprising. The different behavioural additionality that the two policies schemes present in the two countries could provide one piece of explanation for this puzzle.

The empirical application has also offered us useful insights to classify and compare the policy schemes in the two countries, in terms of extension of their impact, across the considered dimensions and levels. For example, only national policies appear to show full-multidimensionality, in the two countries, and are able to tackle the whole array of failures to which firms are exposed. Regional policies are instead unable to and have a different nature in Spain and in Italy. In the former case, their additionality is bidimensional (behavioural and output). In the latter, instead, it is even negative across the different dimensions, showing a full crowding-out impact, which hints at the presence of public failures in the relevant level of government.

Interesting results also emerge by looking at cross-level additionality. For example, the output dimension is one along which there are aspects, for which a full cross-level additionality can be detected: along them, the two levels of government appear to push the treated firms in the same direction. However, unlike in Spain, in Italy a more consistent number of aspects in the realm of innovation output is such to reveal full cross-level crowding out: with both national and regional firms ending out worsening the pre-policy innovative outcomes of the treated firms.

By pooling together all the additionality effects that the policies have, only the Spanish multi-level system of policy exhibits full multi-dimensionality. With the same specification, instead, the Italian one appears only bi-dimensional. In brief, the considered innovation policies have more extensive additionality effects in Spain than in Italy.

\footnotetext{
${ }^{29}$ Of course, this is no exclusive. The reason for which Italian regional innovation policies result so weak deserves a deeper investigation. On the one hand, we should consider the heterogeneity of the regional policies, and thus of their effects. On the other hand, we should retain that the period considered in this analysis (20022004) is only immediately subsequent to the 2001 reform of the Italian Constitution, that gave to regions a substantial autonomy in terms of innovation policy.
} 


\section{References}

Aerts, K. and Schimdt, T. (2008), 'Two for the price of one? Additionality effects of R\&D subsidies: a comparison between Flanders and Germany', Research Policy 37(5), 806822.

Afcha Chávez, S. M. (2011), 'Behavioural additionality in the context of regional innovation policy in Spain', Innovation: Management, Policy \& Practice 13(1), 95-110.

Amin, A. (1999), 'An institutionalist perspective on regional economic development', International Journal for Urban and Regional Research, 23(2), 365-378.

Antonioli, D. and A. Marzucchi (2012). Evaluating the additionality of innovation policy. A review focused on the behavioural dimension. World Review of Science, Technology and Sustainable Development, 9(2-4), 124-148.

Antonioli, D., Marzucchi, A. and Montresor, S. (2012), Regional Innovation Policy and Innovative Behaviour: Looking for Additional Effects, European Planning Studies, Online publication at: http://www.tandfonline.com/doi/abs/10.1080/09654313.2012.722977

Arrow, K. (1962), 'Economic welfare and the allocation of resources for invention', in Nelson R. (Ed), The Rate and Direction of Inventive Activity: Economic and Social Factors, pp. 609-626, NBER, Washington.

Autio, E. (1998), 'Evaluation of RTD in regional systems of innovation', European Planning Studies 6(2), 131-140.

Barbieri, E., Iorio, R. and Lubrano Lavadera, G. (2010), 'Incentivi alla Ricerca \& Sviluppo in Italia: un'indagine sugli effetti della legge 46/82', L'Industria 31(2), 335-366 ['Italian R\&D policy schemes. An analysis on the effects of the law 46/82']

Becker, S. 0. and Ichino, A. (2002) 'Estimation of average treatment effects based on propensity scores', The Stata Journal 2(4), 358-377.

Boschma, R. (2005b), 'Rethinking regional innovation policy', in Fuchs, G. and Shapira P. (Eds), Rethinking Regional Innovation and Change, pp. 249-271, Springer, New York, NY.

Breschi, S., Cassi, L., Malerba, F. and Vonortas, N. (2009), 'Networked research: European policy intervention in ICTs', Technology Analysis and Strategic Management 21(7), 833857.

Bronzini, R. and Iachini, E. (2011), 'Are incentives for R\&D effective? Evidence from a regression discontinuity approach', Bank of Italy Working Papers n.791.

Buisseret, T., Cameron, H. M. and Georghiou, L. (1995), 'What difference does it make? Additionality in the public support of R\&D in large firms', International Journal of Technology Management 10(4-5-6), 587-600.

Busom, I. (2000), 'An empirical evaluation of the effects of R\&D subsidies', Economics of Innovation and New Technology 9(2), 111-148.

Busom, I. and Fernández-Ribas, A. (2008) 'The impact of firm participation in R\&D programmes on R\&D partnership', Research Policy 37(2), 240-257. 
Caliendo, M. and Kopeinig, S. (2008), 'Some practical gudance for the implementation of the propensity score matching', Journal of Economic Surveys 22(1), 31-72.

Cameron, A. C. and Trivedi, P. K. (2005), Microeconometrics. Methods and Applications, Cambridge University Press, Cambridge.

Carboni, O.A. (2011), 'R\&D subsidies and private R\&D expenditures: evidence from Italian manufacturing data', International Review of Applied Economics 25(4), 419-439.

Cefis, E. And Evangelista, R. (2007), 'La valutazione delle politiche per l'innovazione. Un confronto tra Italia e Paesi Bassi', L'Industria 27(2), 243-264 ['The evaluation of innovation policies. A comparison between Italy and Netherlands'].

Cerulli, G. (2010), 'Modelling and measuring the effect of public subsidies on business R\&D: a critical review of the econometric literature', Economic Record, 86(274), 421-449.

Cerulli, G. and Potì B. (2008), 'Evaluating the effect of public subsidies on firm R\&D activity: an application to Italy using the Community Innovation Survey', CERIS Working Paper $09 / 2008$.

Cerulli, G. and Potì, B. (2010), 'The differential impact of privately and publicly funded R\&D on R\&D investment and innovation: the Italian case', Doctoral School of Economics University "la Sapienza" Working Papers n.10.

Clarysse, B., Bilsen, V., Steurs, G. and Larosse J. (2004), 'Measuring Additionality of R\&D Subsides with Surveys: Towards an Evaluation Methodology for IWT Flanders', Innovation Science Technology IWT-Observatory 48, 23-56.

Clarysse, B., Wright, M. and Mustar, P. (2009) 'Behavioural additionality of R\&D subsidies: a learning perspective', Research Policy, 38(10) 1517-1533.

Colombo, M.G., Grilli, L. and Murtinu, S. (2011), 'R\&D subsidies and the performance of high-tech start-ups', Ecomomic Letters 112(1), 97-99.

Cooke, P. (2002), 'Regional innovation systems: general findings and some evidence from the biotechnology clusters', Journal of Technology Transfer 27 (1), 133-145.

Czarnitzki, D. and Licht, G. (2006) 'Additionality of public R\&D grants in a transition economy', Economics of Transition, 14(1), 101-131.

De Blasio, G., Fantino, D. and Pellegrini, G. (2011), 'Evaluating the impact of innovation incentives: evidence from an unexpected shortage of funds', Bank of Italy Working Papers n. 792.

Edquist, C. (1999), 'Systems of innovation: theory and policy for the demand side', Technology in Society 21(1), 63-79.

Edquist, C., Malerba, F., Metcalfe, J. S., Montobbio, F., Steinmueller, W. E. (2004), Sectoral systems: implication for European innovation policy. Cambridge University Press, 2004, pp. 427- 461.

Edquist, C. (2011). Design of innovation policy through diagnostic analysis: identification of systemic problems (or failures). Industrial and Corporate Change 20(6), 1637-1643. 
European Commission (2009). Making public support for innovation in the EU more effective. Lessons learned from a public consultation for action at Community level. Commission Staff Working Document SEC(2009)1197 of 09.09.2009.

European Commission (2010), 'EUROPE 2020. A Strategy for Smart, Sustainable and Inclusive Growth', Communication from the Commission Com(2010) 2020, Brussels

Fernández-Ribas, A. And Shapira, P. (2009), 'The role of national and regional innovation programmes in stimulating international cooperation in innovation', International Journal of Technology Management 48(4), 473-498.

Garcia-Quevedo, J. and Afcha-Chávez, S. (2009), 'El impacto del apoyo público a la I+D empresarial: un análisis comparativo entre las subvenciones estatales y regionales', Investigaciones Regionales 15, 277-294 ['The impact of public funding to firms' R\&D: a comparative analysis of national and regional subsidies'].

Georghiou, L. (2002), 'Impact and additionality of innovation policy', Innovation Science and Technology IWT Observatory 40, 57-65.

Georghiou, L. (2004), 'Evaluation of behavioural additionality. Concept paper', Innovation Science and Technology IWT Observatory 48, 7-22.

Georghiou, L. and Clarysse, B. (2006), 'Introduction and synthesis', in OECD (Ed), Government R\&D Funding and Company Behaviour: Measuring Behavioural Additionality, pp. 9-38, OECD, Paris.

González, X. and Pazó, G. (2008), 'Do public subsidies stimulate R\&D spending?', Research Policy 37(3), 371-389.

Hall, B.H. and Maffioli, A. (2008), 'Evaluating the impact of technology development funds in emerging economies: evidence from Latin America', European Journal of Development Research 20(2), 172-198.

Hall, B.H., Lotti, F. and Mairesse, J. (2009), 'Innovation and productivity in SMEs: empirical evidence for Italy', Small Business Economics 33(1), 13-33

Howells, J. (1999), 'Regional systems of innovation?', in Howells, J., Archibugi D. and Michie J. (Eds), Innovation Policy in a Global Economy, pp. 67-93, Cambridge University Press, Cambridge.

Keiser, R. (2003), 'Multi-level science policy and regional Innovation: the case of Munich Cluster for Pharmaceutical Biotechnology', European Planning Studies 11(7), 841-857

Laranja, M., Uyarra, E. and Flanagan K. (2008), 'Policies for science, technology and innovation: Translating rationales into regional policies in a multi-level setting', Research Policy 37(5), 823-835.

Leuven, E. and Sianesi, B. (2003), 'PSMATCH2: Stata module to perform full Mahalanobis and propensity score matching, common support graphing and covariate imbalance testing'. [Available at (2011): http://ideas.repec.org/c/boc/bocode/s432001.html] .

Magro, E., Aranguren, M. J. and Navarro, M. (2010), 'Does regional S\&T policy affect firms' behaviour?', Paper presented for the Regional Studies Association Annual International Conference 2010, Pécs, Hungary. [Available at (2011): http://www.regional-studiesassoc.ac.uk/events/2010/may-pecs/papers/Magro.pdf] . 
Marzucchi, A. (2012), Evaluating the Additionality of Innovation Policy: An Investigation at Different Levels of Analysis, PhD Thesis University of Trento.

Marzucchi, A., Antonioli, D. and Montresor, S. (2012), Research cooperation within and across regional boundaries. Does innovation policy add something? IPTS Working Paper on Corporate R\&D and Innovation.

Metcalfe, J.S. (1995), 'The economic foundations of economic policy: equilibrium and evolutionary perspectives', in Stoneman, P. (Ed), Handbook of the Economics of Innovation and Technological Change, pp.409-512, Blackwell Handbooks in Economics, Hoboken, NJ.

Merito, M., Giannangeli, S. and Bonaccorsi, A. (2010), 'Do incentive to industrial R\&D enhance research productivity and firm growth? Evidence from the Italian case', International Journal of Technology Management 49(1-2-3), 25-48.

Nelson, R. and Winter, S. (1982), An Evolutionary Theory of Economic Change, The Belknap Press of Harvard University Press, Cambridge, MA.

Parisi, M.L. and Sembenelli, A. 'Is private R\&D spending sensitive to its price? Empirical evidence on panel data for Italy', Empirica 30(4), 357-377

Rubin, D. (1986), 'Comment: which ifs have causal answers', Journal of the American Statistical Association, 81 (396), 961-962

Smith, K. (2000), 'Innovation as a Systemic Phenomenon: Rethinking the Role of Policy', Enterprise \& Innovation Management Studies 1(1), 73-102.

Smith, J.A. and Todd, P. E. (2005), 'Does matching overcome LaLonde's critique of nonexperimental estimators?', Journal of Econometrics 125(1-2), 305-353.

Tamm, D. (2010). System failures in public sector innovation support measures: The case of Estonian innovation system and dairy industry, Diskurs 2010 - 07.

Uyarra, E. (2010), 'What is evolutionary about 'regional systems of innovation'? Implications for regional policy', Journal of Evolutionary Economics 20(1), 115-137.

Woolthuis, K., Lankhuizen M. and Gilsing, V. (2005), 'A system failure framework for innovation policy design', Technovation 25(6), 609-619. 


\section{Appendix}

Tab. A1 Probit estimation of the propensity scores

FUNLOC - Italy

FUNGMT - Italy

FUNLOC - Spain FUNGMT - Spain

\begin{tabular}{|c|c|c|c|c|c|c|c|c|}
\hline & Coeff. & S.E. & Coeff. & S.E. & Coeff. & S.E. & Coeff. & S.E. \\
\hline SMALL & 0.185 & 0.159 & -0.234 & 0.164 & $0.535 * * *$ & 0.101 & $-0.325 * * *$ & 0.095 \\
\hline MEDIUM & $0.330 * * *$ & 0.123 & -0.119 & 0.116 & $0.381 * * *$ & 0.096 & $-0.271 * * *$ & 0.086 \\
\hline InTURN02 & -0.029 & 0.034 & $0.066 *$ & 0.038 & 0.009 & 0.006 & $-0.018 * * *$ & 0.006 \\
\hline GP & $-0.250 * * *$ & 0.085 & -0.002 & 0.088 & -0.008 & 0.064 & $0.288^{* * *}$ & 0.067 \\
\hline MNC & $-0.295^{* *}$ & 0.125 & $-0.346^{* * *}$ & 0.116 & $-0.203^{* *}$ & 0.093 & $-0.419 * * *$ & 0.093 \\
\hline EXPORT & -0.005 & 0.075 & -0.004 & 0.088 & 0.011 & 0.055 & 0.053 & 0.070 \\
\hline RDENG & 0.125 & 0.082 & -0.035 & 0.096 & $0.215^{* * *}$ & 0.065 & $0.280 * * *$ & 0.086 \\
\hline RDCONT & $0.295^{* * *}$ & 0.077 & $0.397^{* * *}$ & 0.089 & 0.069 & 0.063 & $0.357^{* * *}$ & 0.076 \\
\hline HFENT2 & 0.036 & 0.083 & 0.079 & 0.091 & $0.147^{* *}$ & 0.063 & -0.014 & 0.072 \\
\hline HFENT3 & 0.083 & 0.100 & -0.148 & 0.117 & 0.057 & 0.073 & -0.079 & 0.087 \\
\hline HFOUT2 & 0.104 & 0.085 & 0.196 ** & 0.094 & 0.076 & 0.063 & 0.074 & 0.074 \\
\hline HFOUT3 & $-0.311^{* * *}$ & 0.099 & -0.059 & 0.111 & -0.035 & 0.071 & -0.037 & 0.086 \\
\hline SPRO2 & $0.255^{* * *}$ & 0.085 & 0.106 & 0.093 & 0.116 & 0.060 & -0.062 & 0.073 \\
\hline SPRO3 & $0.551 * * *$ & 0.134 & 0.117 & 0.159 & -0.069 & 0.116 & 0.077 & 0.126 \\
\hline SGMT2 & -0.056 & 0.192 & $0.667^{* * *}$ & 0.161 & $0.374^{* * *}$ & 0.093 & $0.496^{* * *}$ & 0.100 \\
\hline SGMT3 & 0.294 & 0.249 & 0.148 & 0.271 & 0.702 *** & 0.197 & $0.576^{* * *}$ & 0.218 \\
\hline CONST. & -0.346 & 0.640 & $-1.603 * *$ & 0.715 & $-1.494 * * *$ & 0.194 & $-1.174 * * *$ & 0.219 \\
\hline $\begin{array}{l}\text { Sectoral } \\
\text { dummies }\end{array}$ & \multicolumn{2}{|c|}{ Included } & \multicolumn{2}{|c|}{ Included } & \multicolumn{2}{|c|}{ Included } & \multicolumn{2}{|c|}{ Included } \\
\hline $\mathrm{N}$ & \multicolumn{2}{|c|}{2006} & \multicolumn{2}{|c|}{1845} & \multicolumn{2}{|c|}{4110} & \multicolumn{2}{|c|}{3795} \\
\hline Prob $>\chi^{2}$ & \multicolumn{2}{|c|}{0.000} & \multicolumn{2}{|c|}{0.000} & \multicolumn{2}{|c|}{0.000} & \multicolumn{2}{|c|}{0.000} \\
\hline Pseudo R ${ }^{2}$ & \multicolumn{2}{|c|}{0.059} & \multicolumn{2}{|c|}{0.077} & \multicolumn{2}{|c|}{0.039} & \multicolumn{2}{|c|}{0.098} \\
\hline
\end{tabular}

$* * *, * *, *$ indicate a significance level of $1 \%, 5 \%, 10 \%$. A VIF test leads to exclude the multicollinearity of the covariates (all the VIF values are lower than 10) 
Tab. A2 Behavioural additionality effects on firms' interactions. Italian regional policies

\begin{tabular}{|c|c|c|c|c|c|c|c|c|}
\hline & \multicolumn{2}{|c|}{$5 N N$} & \multicolumn{2}{|c|}{ Caliper } & \multicolumn{2}{|c|}{ Kernel } & \multicolumn{2}{|c|}{ 5NN Trim } \\
\hline & ATT & S.E. & ATT & S.E. & ATT & S.E. & ATT & S.E. \\
\hline COOPGPNAT & -0.010 & 0.008 & -0.010 & 0.008 & -0.009 & 0.006 & -0.013 & 0.008 \\
\hline COOPGPFOR & 0.001 & 0.005 & 0.001 & 0.005 & 0.000 & 0.004 & 0.001 & 0.005 \\
\hline COOPSUPNAT & -0.016 & 0.016 & -0.016 & 0.015 & -0.005 & 0.013 & -0.024 & 0.017 \\
\hline COOPSUPFOR & 0.001 & 0.004 & 0.001 & 0.004 & 0.000 & 0.003 & 0.001 & 0.003 \\
\hline COOPCUSNAT & -0.021 & 0.014 & $-0.021 *$ & 0.012 & -0.011 & 0.009 & $-0.027^{* *}$ & 0.011 \\
\hline COOPCUSFOR & -0.008 & 0.007 & -0.008 & 0.008 & -0.005 & 0.007 & -0.010 & 0.008 \\
\hline COOPCOMNAT & $-0.026^{* *}$ & 0.012 & $-0.026^{* *}$ & 0.010 & -0.012 & 0.009 & $-0.031 * * *$ & 0.011 \\
\hline COOPCOMFOR & -0.001 & 0.006 & -0.001 & 0.006 & 0.000 & 0.005 & -0.001 & 0.006 \\
\hline COOPINSNAT & -0.010 & 0.014 & -0.010 & 0.014 & -0.005 & 0.012 & -0.017 & 0.014 \\
\hline COOPINSFOR & 0.003 & 0.004 & 0.003 & 0.004 & 0.004 & 0.004 & 0.004 & 0.004 \\
\hline COOPUNINAT & -0.013 & 0.012 & -0.013 & 0.012 & -0.012 & 0.010 & -0.018 & 0.013 \\
\hline COOPUNIFOR & 0.001 & 0.004 & 0.001 & 0.004 & 0.001 & 0.003 & 0.001 & 0.004 \\
\hline COOPPUBNAT & -0.004 & 0.006 & -0.004 & 0.005 & -0.004 & 0.004 & -0.006 & 0.005 \\
\hline COOPPUBFOR & 0.000 & 0.003 & 0.000 & 0.003 & 0.000 & 0.002 & 0.000 & 0.003 \\
\hline INFOSUP & $-0.053 *$ & 0.030 & $-0.059 *$ & 0.030 & $-0.041 *$ & 0.024 & $-0.053^{*}$ & 0.030 \\
\hline INFOCUS & -0.005 & 0.031 & 0.000 & 0.034 & 0.008 & 0.027 & -0.010 & 0.033 \\
\hline INFOCOM & -0.009 & 0.028 & -0.004 & 0.031 & 0.008 & 0.025 & -0.020 & 0.030 \\
\hline INFOINS & $0.114^{* * *}$ & 0.029 & $0.119 * * *$ & 0.030 & $0.116^{* * *}$ & 0.024 & $0.118^{* * *}$ & 0.029 \\
\hline INFOUNI & $-0.039 * *$ & 0.019 & $-0.038 * *$ & 0.019 & $-0.033 * *$ & 0.013 & $-0.040 * *$ & 0.017 \\
\hline$N$ treat. on support & \multicolumn{2}{|c|}{598} & \multicolumn{2}{|c|}{598} & \multicolumn{2}{|c|}{598} & \multicolumn{2}{|l|}{570} \\
\hline$N$ treated total & \multicolumn{2}{|c|}{599} & \multicolumn{2}{|c|}{599} & \multicolumn{2}{|c|}{599} & \multicolumn{2}{|c|}{599} \\
\hline$N$ non treated & \multicolumn{2}{|c|}{1407} & \multicolumn{2}{|c|}{1407} & \multicolumn{2}{|c|}{1407} & \multicolumn{2}{|c|}{1407} \\
\hline
\end{tabular}

$* * *, * *, *$ indicate a significance level of $1 \%, 5 \%, 10 \%$. Standard errors are calculated with a $200-$ replication bootstrap procedure. 
Tab. A3 Behavioural additionality effects on firms' interactions. Italian national policies

\begin{tabular}{|c|c|c|c|c|c|c|c|c|}
\hline & \multicolumn{2}{|c|}{$5 \mathrm{NN}$} & \multicolumn{2}{|c|}{ Caliper } & \multicolumn{2}{|c|}{ Kernel } & \multicolumn{2}{|c|}{ 5NN Trim } \\
\hline & ATT & S.E. & ATT & S.E. & ATT & S.E. & ATT & S.E. \\
\hline COOPGPNAT & 0.012 & 0.014 & 0.012 & 0.015 & 0.013 & 0.013 & 0.010 & 0.015 \\
\hline COOPGPFOR & 0.001 & 0.009 & 0.001 & 0.010 & 0.004 & 0.009 & -0.003 & 0.009 \\
\hline COOPSUPNAT & $0.046^{* *}$ & 0.020 & $0.045^{* *}$ & 0.023 & $0.049^{* * *}$ & 0.018 & $0.046^{* *}$ & 0.023 \\
\hline COOPSUPFOR & $0.014^{* *}$ & 0.007 & $0.014^{* *}$ & 0.007 & $0.013^{*}$ & 0.007 & $0.012^{*}$ & 0.007 \\
\hline COOPCUSNAT & 0.017 & 0.017 & 0.016 & 0.017 & 0.022 & 0.014 & 0.015 & 0.016 \\
\hline COOPCUSFOR & 0.010 & 0.013 & 0.010 & 0.013 & 0.013 & 0.011 & 0.005 & 0.011 \\
\hline COOPCOMNAT & 0.011 & 0.014 & 0.010 & 0.015 & 0.009 & 0.012 & 0.014 & 0.014 \\
\hline COOPCOMFOR & -0.004 & 0.007 & -0.004 & 0.007 & -0.003 & 0.006 & -0.007 & 0.007 \\
\hline COOPINSNAT & $0.072^{* * *}$ & 0.024 & $0.070 * * *$ & 0.021 & $0.081^{* * *}$ & 0.020 & $0.076^{* * *}$ & 0.022 \\
\hline COOPINSFOR & 0.008 & 0.007 & 0.008 & 0.007 & 0.008 & 0.006 & 0.006 & 0.008 \\
\hline COOPUNINAT & $0.093 * * *$ & 0.025 & $0.093^{* * *}$ & 0.023 & $0.103^{* * *}$ & 0.021 & $0.096^{* * *}$ & 0.023 \\
\hline COOPUNIFOR & 0.001 & 0.006 & 0.001 & 0.005 & 0.002 & 0.005 & 0.001 & 0.006 \\
\hline COOPPUBNAT & 0.018 & 0.012 & 0.017 & 0.012 & $0.017^{*}$ & 0.010 & $0.020 *$ & 0.011 \\
\hline COOPPUBFOR & 0.000 & 0.001 & 0.000 & 0.001 & -0.001 & 0.001 & 0.000 & 0.001 \\
\hline INFOSUP & -0.005 & 0.034 & -0.004 & 0.034 & -0.007 & 0.027 & -0.004 & 0.035 \\
\hline INFOCUS & 0.028 & 0.033 & 0.028 & 0.032 & 0.019 & 0.030 & 0.036 & 0.034 \\
\hline INFOCOM & 0.006 & 0.033 & 0.004 & 0.033 & 0.003 & 0.029 & 0.016 & 0.032 \\
\hline INFOINS & $0.100 * * *$ & 0.034 & $0.099 * * *$ & 0.033 & $0.094^{* * *}$ & 0.028 & $0.111^{* * *}$ & 0.037 \\
\hline INFOUNI & $0.063^{* *}$ & 0.026 & $0.062^{* *}$ & 0.027 & $0.070 * * *$ & 0.021 & $0.059 * *$ & 0.027 \\
\hline$N$ treat. on support & \multicolumn{2}{|c|}{433} & \multicolumn{2}{|c|}{433} & \multicolumn{2}{|c|}{433} & \multicolumn{2}{|c|}{417} \\
\hline$N$ treated total & \multicolumn{2}{|c|}{438} & \multicolumn{2}{|c|}{438} & \multicolumn{2}{|c|}{438} & \multicolumn{2}{|c|}{438} \\
\hline$N$ non treated & \multicolumn{2}{|c|}{1407} & \multicolumn{2}{|c|}{1407} & \multicolumn{2}{|c|}{1407} & \multicolumn{2}{|c|}{1407} \\
\hline
\end{tabular}

$* * *, * *, *$ indicate a significance level of $1 \%, 5 \%, 10 \%$. Standard errors are calculated with a 200replication bootstrap procedure. 
Tab. A4 Behavioural additionality effects on firms'interactions. Spanish regional policies

\begin{tabular}{|c|c|c|c|c|c|c|c|c|}
\hline & \multicolumn{2}{|c|}{$5 N N$} & \multicolumn{2}{|c|}{ Caliper } & \multicolumn{2}{|c|}{ Kernel } & \multicolumn{2}{|c|}{ 5NN Trim } \\
\hline & ATT & S.E. & ATT & S.E. & ATT & S.E. & ATT & S.E. \\
\hline COOPGPNAT & $0.018 * *$ & 0.009 & $0.019 * *$ & 0.008 & $0.016^{* *}$ & 0.007 & $0.018^{* *}$ & 0.008 \\
\hline COOPGPFOR & -0.002 & 0.006 & -0.002 & 0.007 & -0.002 & 0.005 & -0.002 & 0.007 \\
\hline COOPSUPNAT & $0.039 * * *$ & 0.014 & $0.041 * * *$ & 0.015 & $0.041^{* * *}$ & 0.012 & $0.037^{* *}$ & 0.015 \\
\hline COOPSUPFOR & 0.008 & 0.009 & 0.008 & 0.009 & 0.008 & 0.008 & 0.007 & 0.010 \\
\hline COOPCUSNAT & 0.011 & 0.012 & 0.012 & 0.011 & 0.012 & 0.009 & 0.012 & 0.011 \\
\hline COOPCUSFOR & 0.003 & 0.008 & 0.003 & 0.007 & 0.004 & 0.006 & 0.000 & 0.008 \\
\hline COOPCOMNAT & $0.016 *$ & 0.009 & $0.018 *$ & 0.010 & $0.018 * *$ & 0.008 & $0.019^{* *}$ & 0.009 \\
\hline COOPCOMFOR & 0.003 & 0.005 & 0.003 & 0.004 & 0.001 & 0.004 & 0.003 & 0.005 \\
\hline COOPINSNAT & $0.053 * * *$ & 0.012 & $0.053 * * *$ & 0.013 & $0.053 * * *$ & 0.011 & $0.052 * * *$ & 0.012 \\
\hline COOPINSFOR & $0.009 *$ & 0.005 & $0.010 *$ & 0.005 & $0.008^{*}$ & 0.005 & 0.008 & 0.005 \\
\hline COOPUNINAT & $0.057^{* * *}$ & 0.013 & $0.058^{* * *}$ & 0.014 & $0.061^{* * *}$ & 0.012 & $0.055^{* * *}$ & 0.013 \\
\hline COOPUNIFOR & -0.001 & 0.003 & -0.001 & 0.002 & -0.001 & 0.002 & -0.001 & 0.003 \\
\hline COOPPUBNAT & $0.016^{* *}$ & 0.007 & $0.015^{* *}$ & 0.006 & $0.014 * *$ & 0.006 & $0.014 * *$ & 0.007 \\
\hline COOPPUBFOR & 0.000 & 0.001 & 0.000 & 0.001 & 0.001 & 0.001 & 0.000 & 0.001 \\
\hline INFOSUP & 0.013 & 0.023 & 0.014 & 0.024 & 0.022 & 0.018 & 0.012 & 0.024 \\
\hline INFOCUS & 0.027 & 0.024 & 0.029 & 0.023 & 0.026 & 0.019 & 0.027 & 0.024 \\
\hline INFOCOM & 0.010 & 0.022 & 0.012 & 0.024 & 0.001 & 0.016 & 0.009 & 0.025 \\
\hline INFOINS & $0.052 * *$ & 0.020 & $0.053 * *$ & 0.021 & $0.065^{* * *}$ & 0.018 & $0.062^{* * *}$ & 0.020 \\
\hline INFOUNI & $0.055 * * *$ & 0.016 & $0.056 * * *$ & 0.017 & $0.065 * * *$ & 0.015 & $0.062 * * *$ & 0.017 \\
\hline$N$ treat. on support & \multicolumn{2}{|c|}{876} & \multicolumn{2}{|c|}{874} & \multicolumn{2}{|c|}{876} & \multicolumn{2}{|c|}{836} \\
\hline$N$ treated total & \multicolumn{2}{|c|}{879} & \multicolumn{2}{|c|}{879} & \multicolumn{2}{|c|}{879} & \multicolumn{2}{|c|}{879} \\
\hline$N$ non treated & \multicolumn{2}{|c|}{3231} & \multicolumn{2}{|c|}{3231} & \multicolumn{2}{|c|}{3231} & \multicolumn{2}{|c|}{3231} \\
\hline
\end{tabular}

$* * *, * *, *$ indicate a significance level of 1\%,5\%, 10\%. Standard errors are calculated with a 200replication bootstrap procedure. 
Tab. A5 Behavioural additionality effects on firms'interactions. Spanish national policies $\mathbf{5 N N}$

Caliper

Kernel

5NN Trim

\begin{tabular}{|c|c|c|c|c|c|c|c|c|}
\hline & ATT & S.E. & ATT & S.E. & ATT & S.E. & ATT & S.E. \\
\hline COOPGPNAT & $0.029 * *$ & 0.014 & $0.029 *$ & 0.015 & $0.026^{* *}$ & 0.012 & 0.023 & 0.014 \\
\hline COOPGPFOR & 0.012 & 0.013 & 0.012 & 0.014 & 0.010 & 0.010 & 0.013 & 0.013 \\
\hline COOPSUPNAT & $0.059 * * *$ & 0.020 & $0.059 * * *$ & 0.019 & $0.052 * *$ & 0.017 & $0.057^{* * *}$ & 0.018 \\
\hline COOPSUPFOR & 0.013 & 0.015 & 0.013 & 0.014 & 0.014 & 0.012 & 0.010 & 0.014 \\
\hline COOPCUSNAT & 0.025 & 0.016 & 0.025 & 0.017 & 0.016 & 0.014 & 0.028 & 0.017 \\
\hline COOPCUSFOR & 0.015 & 0.013 & 0.015 & 0.013 & 0.012 & 0.010 & 0.010 & 0.011 \\
\hline COOPCOMNAT & $0.029 * *$ & 0.013 & $0.029 * *$ & 0.012 & $0.026^{* *}$ & 0.010 & $0.027 * *$ & 0.011 \\
\hline COOPCOMFOR & $0.022^{* *}$ & 0.009 & $0.022 * *$ & 0.010 & $0.021 * * *$ & 0.007 & $0.022 * *$ & 0.010 \\
\hline COOPINSNAT & $0.053^{* * *}$ & 0.017 & $0.053^{* * *}$ & 0.019 & $0.054 * * *$ & 0.015 & $0.048^{* * *}$ & 0.016 \\
\hline COOPINSFOR & $0.016^{*}$ & 0.009 & 0.016 & 0.010 & $0.015 *$ & 0.008 & 0.008 & 0.009 \\
\hline COOPUNINAT & $0.086^{* * *}$ & 0.021 & $0.088 * * *$ & 0.020 & $0.090 * * *$ & 0.017 & $0.082 * * *$ & 0.019 \\
\hline COOPUNIFOR & 0.004 & 0.005 & 0.004 & 0.006 & 0.004 & 0.005 & 0.002 & 0.005 \\
\hline COOPPUBNAT & $0.020 *$ & 0.011 & 0.020 * & 0.010 & $0.020^{* *}$ & 0.010 & 0.015 & 0.010 \\
\hline COOPPUBFOR & 0.000 & 0.002 & 0.000 & 0.003 & 0.001 & 0.002 & 0.000 & 0.002 \\
\hline INFOSUP & $0.054^{*}$ & 0.028 & 0.057 & 0.029 & 0.035 & 0.022 & $0.056 *$ & 0.030 \\
\hline INFOCUS & $0.058^{* *}$ & 0.028 & $0.062^{* *}$ & 0.027 & $0.054^{* *}$ & 0.023 & $0.064^{* *}$ & 0.034 \\
\hline INFOCOM & 0.041 & 0.027 & 0.036 & 0.030 & 0.025 & 0.023 & 0.035 & 0.029 \\
\hline INFOINS & $0.055 * *$ & 0.024 & $0.055^{* *}$ & 0.026 & $0.059 * * *$ & 0.022 & $0.059 * *$ & 0.028 \\
\hline INFOUNI & $0.075 * * *$ & 0.024 & $0.079 * * *$ & 0.022 & $0.088^{* * *}$ & 0.020 & $0.068^{* * *}$ & 0.026 \\
\hline$N$ treat. on support & \multicolumn{2}{|c|}{564} & \multicolumn{2}{|c|}{564} & \multicolumn{2}{|c|}{564} & \multicolumn{2}{|c|}{536} \\
\hline$N$ treated total & \multicolumn{2}{|c|}{564} & \multicolumn{2}{|c|}{564} & \multicolumn{2}{|c|}{564} & \multicolumn{2}{|c|}{564} \\
\hline$N$ non treated & \multicolumn{2}{|c|}{3231} & \multicolumn{2}{|c|}{3231} & \multicolumn{2}{|c|}{3231} & \multicolumn{2}{|c|}{3231} \\
\hline
\end{tabular}

***, **, * indicate a significance level of 1\%, 5\%, 10\%. Standard errors are calculated with a 200replication bootstrap procedure. 
Recent papers in the SPRU Working Paper Series:

SWPS 2013-01. Gabriele Pellegrino and Maria Savona. September 2013. "Is money all? Financing versus knowledge and demand constraints to innovations".

SWPS 2013-02. Adrian Smith and Sabine Hielscher. September 2013. "Grassroots digital fabrication and makerspaces: reconfiguring, relocating and recalibrating innovation".

SWPS 2013-03. Paul Nightingale and Alex Coad. September 2013. "Muppets and Gazelles: Political and Methodological Biases in Entrepreneurship Research". 